Insight, part of a Special Feature on Crossing Scales and Disciplines to Achieve Forest Sustainability

\title{
A Toolkit Modeling Approach for Sustainable Forest Management Planning: Achieving Balance between Science and Local Needs
}

\author{
Brian R. Sturtevant ${ }^{1}$, Andrew Fall ${ }^{2}$, Daniel D. Kneeshaw ${ }^{3}, \underline{\text { Neal P. P. Simon }}^{4}$, Michael J.Papaik $^{3}$, \\ $\underline{\text { Kati Berninger }}^{3}$, Frédérik Doyon $^{5}, \underline{\text { Don G. Morgan }}^{6}$, and $\underline{\text { Christian Messier }}^{3}$
}

\begin{abstract}
To assist forest managers in balancing an increasing diversity of resource objectives, we developed a toolkit modeling approach for sustainable forest management (SFM). The approach inserts a meta-modeling strategy into a collaborative modeling framework grounded in adaptive management philosophy that facilitates participation among stakeholders, decision makers, and local domain experts in the meta-model building process. The modeling team works iteratively with each of these groups to define essential questions, identify data resources, and then determine whether available tools can be applied or adapted, or whether new tools can be rapidly created to fit the need. The desired goal of the process is a linked series of domain-specific models (tools) that balances generalized "top-down" models (i.e., scientific models developed without input from the local system) with case-specific customized "bottom-up" models that are driven primarily by local needs. Information flow between models is organized according to vertical (i.e., between scale) and horizontal (i.e., within scale) dimensions. We illustrate our approach within a 2.1 million hectare forest planning district in central Labrador, a forested landscape where social and ecological values receive a higher priority than economic values. However, the focus of this paper is on the process of how SFM modeling tools and concepts can be rapidly assembled and applied in new locations, balancing efficient transfer of science with adaptation to local needs. We use the Labrador case study to illustrate strengths and challenges uniquely associated with a meta-modeling approach to integrated modeling as it fits within the broader collaborative modeling framework. Principle advantages of the approach include the scientific rigor introduced by peer-reviewed models, combined with the adaptability of meta-modeling. A key challenge is the limited transparency of scientific models to different participatory groups. This challenge can be overcome by frequent and substantive two-way communication among different groups at appropriate times in the model-building process, combined with strong leadership that includes strategic choices when assembling the modeling team. The toolkit approach holds promise for extending beyond case studies, without compromising the bottom-up flow of needs and information, to inform SFM planning using the best available science.
\end{abstract}

Key Words: decision support; ecosystem management; forest sustainability; interdisciplinary modeling; land planning; participatory modeling; scaling

\section{INTRODUCTION}

Society demands that forest planners balance more diverse resource objectives than ever before (Côté and Bouthillier 1999, Kneeshaw et al. 2000, Schulte et al. 2006). Modern sustainable forest management (SFM) has, therefore, evolved from basic timber supply to more integrated land-use planning with social, economic, and ecological dimensions
(Lämås and Eriksson 2003). Despite dramatic advancements in computing power, GIS technology, and simulation modeling, decision support tools for SFM have lagged behind the growing diversity of forest planning objectives (Province of British Columbia 1996, Baker and Landers 2004). A root cause underlying this lag is the sheer complexity of the problem. Multi-scalar ecological and human systems form complex relationships (Gunderson

\footnotetext{
${ }^{1}$ Northern Research Station, U.S. Forest Service, ${ }^{2}$ Gowlland Technologies Ltd, ${ }^{3}$ Centre d'Étude de la Forêt (CEF), University of Quebec at Montreal, ${ }^{4}$ Newfoundland and Labrador Department of Natural Resources, ${ }^{5}$ Institut Québécois d'Aménagement de la Forêt Feuillue, ${ }^{6}$ British Columbia Ministry of Forests
} 
and Holling 2002), making them difficult to understand, let alone model. Nonetheless, forest management requires sound guidance for strategic planning, because choices made today will have lasting effects on future ecosystem services and opportunities (Spies et al. 1994). There is a pressing need for approaches to support strategic landscape planning that can maximize innovation for a particular situation (i.e., address specific questions and use local information) and minimize reinvention (i.e., make use of existing models and techniques).

Forest planners often look to the many existing models for decision support (Messier et al. 2003). The primary limitation with this approach is that all models, as simplifications of reality, are limited to the domains for which they were created. Modeling domains have multiple dimensions, including space and time, traditional scientific disciplines, and type of system or location (Messier et al. 2003, Mladenoff 2004). Forest ecology models designed for research (e.g., Aber et al. 1995, Pacala et al. 1996, He and Mladenoff 1999, Kimmins et al. 1999) lack the social and economic dimensions of SFM and often do not match the scales of interest to planners. Such models also require expertise and specialized data for parameterization and interpretation that is often not available to forest planners or simply irrelevant to them. In contrast, forest optimization models that combine growth and yield with harvest scheduling or timber supply analyses were designed specifically for productionoriented forestry and are the current staple of most forest planning (e.g., Feunekes and Cogswell 1997). Such models are well-suited for productionoriented questions (i.e., their intended domain), but they lack integration with key ecological processes, including succession and natural disturbance, which affects their reliability (Fall et al. 2004).

Using off-the-shelf models is a top-down approach, where information primarily flows from researchers and planners to local communities. It benefits from the expertise and resources that went into model development, but risks being unable to adapt to the unique questions, knowledge, context, and crossdisciplinary integration inherent to any specific SFM planning initiative. An alternative approach is case-specific modeling (Antle et al. 2001, Kruse et al. 2004), where information primarily flows from local sources to researchers and planners to build a model from the bottom up in support of local needs. Case-specific modeling customizes the modeling domain to the specific planning needs, but the time and cost of developing new models can limit their ability to rapidly inform the decision-making process (Fall et al. 2001), and by definition, customized models are not intended for re-use elsewhere. Therefore, planners are handed the "devil's choice" between top-down and bottom-up modeling approaches. No single model can address the needs of all forest planning situations, and attempts to build such models will likely suffer from over-generality, scale mismatch issues, or endless additions to address new data and questions (Derry 1998, Commission d'étude sur la gestion de la forêt publique québécoise 2004). Given the exploding demand for simulation modeling support in SFM, it is also doubtful that the technical capacity exists to produce customized models for every planning situation.

Managers need a general and flexible framework to support SFM planning, one that answers the questions being asked at the right scale and in a timely and cost-efficient fashion, while still integrating the three dimensions (social, economic, and ecological) that shape managed forest ecosystems. We propose a "toolkit" approach that builds on existing and readily adaptable modeling "tools" that have been developed and applied to previous research and planning initiatives across Canadian boreal forests and similar ecosystems. This approach is a hybrid between selecting a model "off the shelf" and building a customized model. The goal is to keep the scientific and rapid deployment advantages of top-down approaches, as well as the adaptive, shared-ownership advantages of bottom-up approaches. Although our experience comes primarily from North American boreal forests, we believe that such an approach should rapidly inform sustainable forestry in any social, economic, and ecological context because it can adapt to new circumstances while simultaneously taking advantage of cumulative experience to answer planning questions quickly and appropriately.

Our purpose is to outline the process of identifying questions, finding the tools and information to answer them, and then ensuring that the interacting suite of domain specific tools informs the global objectives of the planning process (i.e., the toolkit approach to SFM). We first overview a process that inserts a meta-modeling approach into a collaborative modeling framework that focuses on local planning needs. We then illustrate the process of applying that framework to a case study in central 
Labrador, an area dominated by pristine forests that is currently managed by a cooperative provincial government-First Nation partnership. In closing, we elaborate on our lessons learned when coupling a suite of models in contrast to using or developing one integrated model in the context of participatory modeling in support of SFM.

\section{SFM TOOLKIT APPROACH}

\section{Context}

Motivation for our toolkit approach arose from a suite of studies across boreal and similar forested ecosystems (Coates et al. 2003, Van Damme et al. 2003, Fall et al. 2004, Pennanen et al. 2004, Sturtevant et al. 2004, Gustafson et al. 2006; Fig. 1). Key ecological processes common to all systems included succession, environmental constraints on vegetation, and natural disturbances (e.g., fire, wind, and insects). Likewise, management activities in each system were determined by social (e.g., hunting, recreation, water flow, and other various ecosystem services) and economic values (e.g., timber production and tourism). Human and ecological dimensions of these managed ecosystems were also interactive. For example, fire suppression and timber salvaging often changed stand-level processes, whereas the loss of or perceived threat to key species often changed the social perception of the ecosystem, which in turn changed harvesting practices. Finally, the scale of forest management had profound effects on ecosystem structure and function. By simply scaling up the expected mean behavior of stands and ignoring fine-scale processes, traditional forestry has created more homogeneous stands and landscapes (Hunter 1990, Cissel et al. 1994, Bergeron et al. 1999). Similarly, broad-scale processes such as disturbance, fragmentation, and long-distance dispersal constrain forest ecosystem behavior (Peterson 2002). Attempts to include all of these processes into a single model are fraught with difficulty because of the persistent boundaries between traditional scientific disciplines and nonlinearities inherent in scaling (Lertzman and Fall 1998). These difficulties begged the question: Could a toolkit of domainspecific modeling tools provide a more adaptable alternative to either a simplistic modeling approach (i.e., one domain-specific forecasting tool) or a fully integrated modeling approach (i.e., an interdisciplinary but case-specific model)?

\section{Collaborative Framework for SFM Modeling}

The existence of potential tools, and the capacity to use them, is necessary but not sufficient to support SFM planning. A collaborative process is critical to ensure that appropriate issues are addressed (Fall et al. 2001). Collaborative modeling (e.g., Holling 1978, Grudin 1991, Maxwell and Costanza 1997) is an iterative process that aims to include the appropriate people at the appropriate time in the modeling process (Fig. 2). The first step in the process is to clarify the questions and issues of concern from the stakeholders and decision makers. The next step is to define key ecological processes, and social and economic values, along with their respective scales and interactions. Understanding scale as it relates to these drivers is fundamental to the approach, as it underlies both social perceptions and the strength of interactions among the drivers (Allen and Hoekstra 1992, Gunderson and Holling 2002). Collectively, these processes and stakeholder interests form the conceptual model for the study system that can be formalized through more intensive work with local domain experts. During this stage, available data is identified (or a protocol to collect it is designed). Given data resources, important social values, and essential processes, the modeling team can then create a model that captures the system dynamics and produces the key indicators for scenario assessment. The iterative aspect of the modeling process proceeds from verification that the implemented model captures the essential dynamics of the conceptual model, to scenario design and assessment, to presentation of results (Fig. 2). Key benefits of this process include rapid response, local adaptation, and mutual learning. A typical drawback is that scientific rigor may be restricted by the timeline required to build fully customized models. A toolkit approach has the potential to extend and empower the collaborative process by allowing the rapid assembly of domainspecific modeling tools that, in combination, account for different scales and domains.

\section{Inserting a Model Toolkit into the Collaborative Modeling Framework}

A toolkit approach extends the collaborative modeling framework by explicitly incorporating a priori modeling knowledge captured in pre-existing tools to create "meta-models", defined as "models derived from other models" (Urban et al. 1999). 
Fig. 1. Modeling teams in new landscapes can avoid "reinventing the wheel" by building on the knowledge, insights, tools, and experiences of previous modeling initiatives. The SFM toolkit approach discussed in this paper is built upon this philosophy. Commonality among case studies is visualized as a wheel, where insights and modeling tools from each region (spokes) make up the toolkit to be applied to a new case study (hub). Studies represented in this diagram share some common ecological attributes (i. e., boreal forests, fire) and anthropogenic interactions with the landscape (e.g., harvesting, conservation), but differ enough in context, questions, and issues addressed to make unique contributions to the new case study.

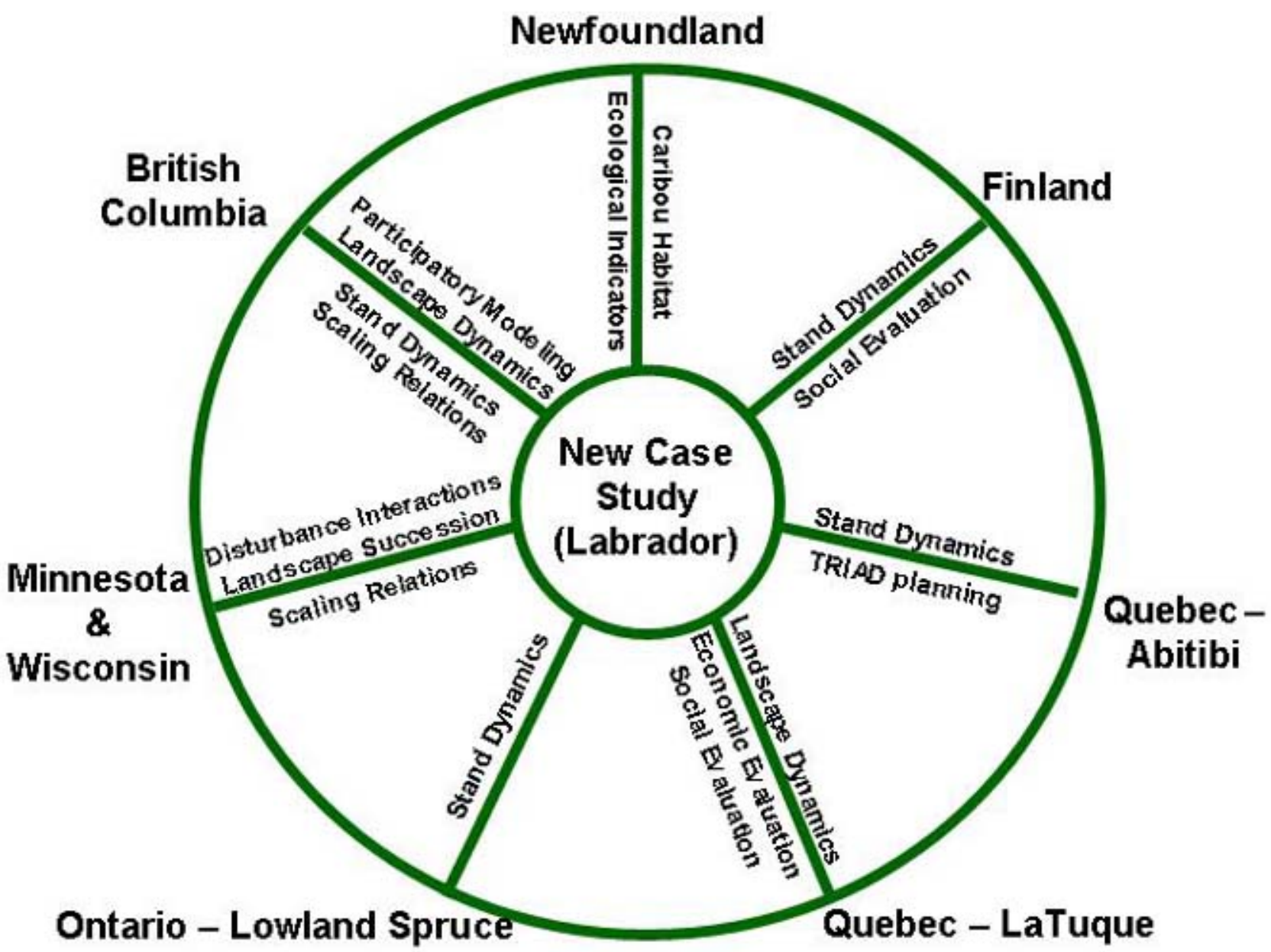

Meta-modeling has been increasingly applied to scale fine-scaled processes and behaviors to broader spatial scales (e.g., Williams et al. 1997, He et al. 1999, Urban 2005), and also to modularize different components of systems that have limited interactive feedback (e.g., forest succession models used to project habitat suitability for wildlife metapopulations;
Akçakaya 2001, Larsen et al. 2004). Meta-modeling may be integrated with the collaborative SFM planning process as the model system evolves from the conceptual through the formalized and then the implemented meta-model, where models (i.e., tools) for each component are selected from a model toolkit, or the need for adapting a model or even 
Fig. 2. The nested, iterative model development process proposed by Fall et al. (2001). Groups participate in all circles that surround them. The initial interest and desire for strategic SFM planning comes from the stakeholders and decision makers. All participants (stakeholders, decision makers, domain experts, core team members) set objectives, select scenarios, develop conceptual models, and discuss model results. Domain experts and the core team develop and verify the formal models. The core modeling team is responsible for organizing workshops and communication, gathering required information, implementing models, ensuring equivalence to formal conceptual models, running simulations, analyzing outputs, and documentation. (Reprinted with permission from Transactions in GIS 5(1): 67-86.)

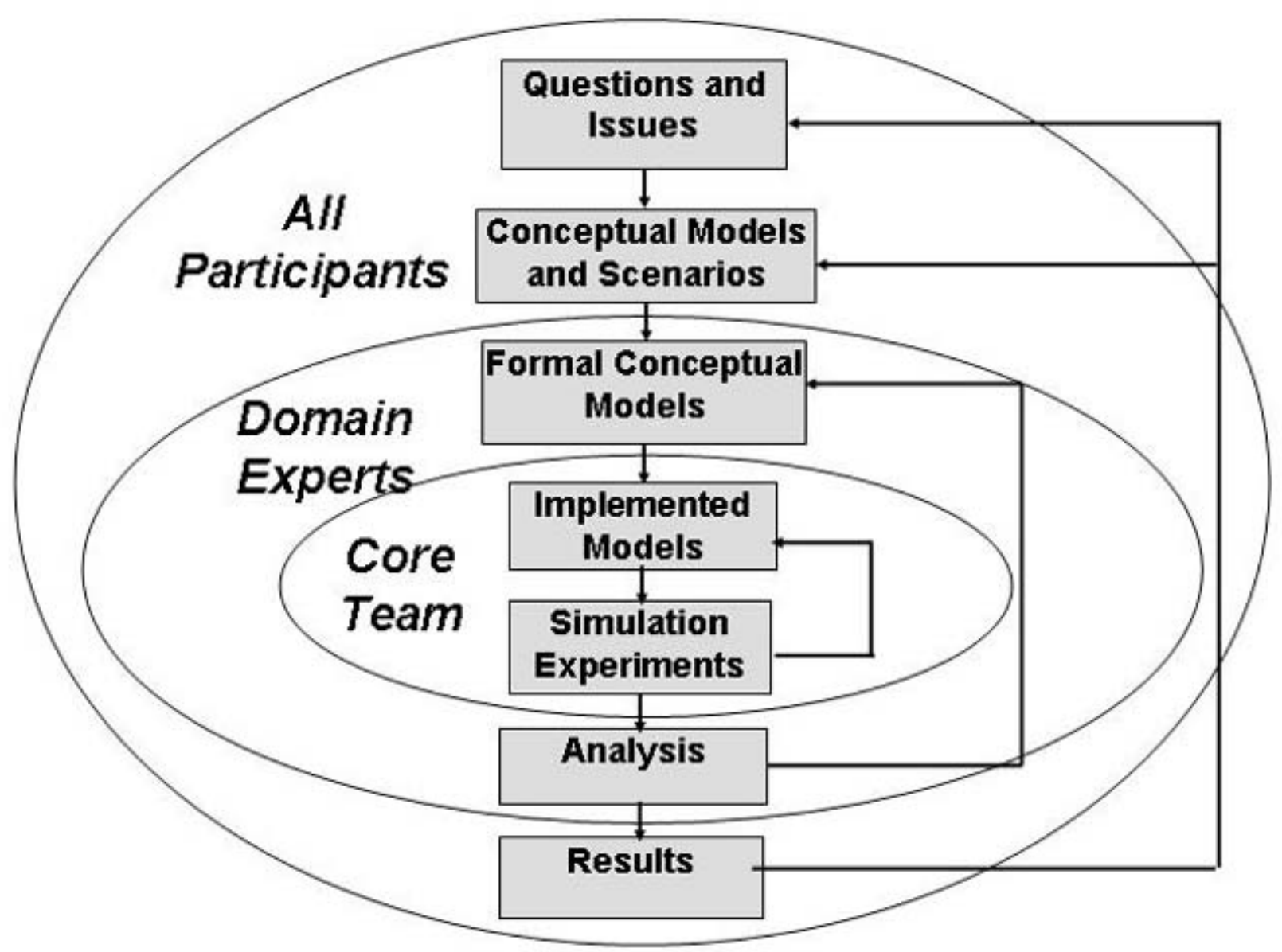


developing a new one is identified. To be useful in this process, component models must be capable of interacting via a loose-coupling (e.g., Clarke and Gaydos 1998), in which output from one component becomes input to another (e.g., a time series output of raster maps, or a statistical distribution describing a fine-scale process). In this way, the benefit of adaptation to local needs is interlaced with collective experience embedded in the tools applied.

Meta-modeling simplifies a model system by encapsulating processes within their appropriate disciplinary and spatio-temporal domains (i.e., within a single tool), while allowing more limited interactions between domains by means of data exchange between models. For example, a finescale forest gap model can statistically parameterize tree species establishment probabilities for a coarser-scaled, rule-based succession model (He et al. 1999). Such one-way flow of information is known as "pipelining", a term used by computer scientists to describe loose-coupling of independent processes, where the output of one becomes the input to others (Orton and Weick 1990, Salus 1994). Semi-dependent components can also interact through two-way information flow. In the above example, long-distance seed dispersal simulated by the coarser-scaled model could provide a higherorder context (i.e., seed rain) for fine-scaled gap dynamics. In this way, questions centered at specific scales can still be informed by processes occurring at different scales. The assumption of limited crossscale interactions is consistent with a hierarchical view of ecological systems, where processes occurring at vastly different rates have limited interactions (O'Neil et al. 1986). We characterize such cross-scale meta-modeling as "vertical data exchange", to separate it conceptually from withinscale meta-modeling or "horizontal data exchange" (e.g., forest dynamics affecting habitat suitability). Sensitivity analyses applied to transferred data can then evaluate the degree to which the pipelining strategy influences modeling results.

A meta-modeling strategy can be embedded within a collaborative modeling framework to foster local participation. Questions and issues raised during the conceptual model stage (Fig. 2) bound the suite of modeling tools applicable to the "system of interest", defined as forest ecosystem to be managed and the social, ecological, and economic drivers affecting SFM decisions. The modeling team and domain experts then elaborate on this initial conceptual model, separating key processes and relationships into the three main components of the formal conceptual model: (1) interactive model system, (2) indicators of values, and (3) management scenarios. The interactive model system is defined as those processes of the system that interact dynamically. Indicators are measurable characteristics of stakeholder interests output from the interactive model system, including simple outputs (e.g., harvest flow, age-class structure), translation of outputs (e.g., patch size distribution), and results of domain-specific indicator models applied to those outputs (e.g., wildlife habitat or population models). Management scenarios simulate human activities that control specific components of the interactive meta-model, with the indicators acting as the interface between metamodel behavior and human interpretation to evaluate alternative management scenarios.

Once the key processes and relationships are defined, the formal conceptual model can be decomposed along logical boundaries between processes and then modeled using domain-specific tools (e.g., forest landscape change, habitat supply, growth and yield stand modeling, etc.). Strong interactions between processes should ideally be modeled within the same tool, whereas weak interactions between processes become logical breaking points between modeling tools. Overlap between the modeling domains of different tools is common, creating redundancy in the model assemblage that can be exploited in different ways. For example, one can compare output from two models where their domains overlap. Agreement between models with different architecture can increase confidence in our understanding of ecosystem dynamics as represented by the models, whereas disagreement between models can point to areas of uncertainty, leading (if time allows) to improved model structure (Rastetter 2003). Furthermore, a model can inform implementation even if it is not part of the final meta-model. For example, a model can evaluate the sensitivity of a system to a process or interaction before it is included in the meta-model design. The following section illustrates the process of applying a toolkit at a specific location. 


\section{LABRADOR DISTRICT 19A CASE STUDY}

\section{SFM Issue and Local Needs}

District $19 \mathrm{~A}$ is a 2.1 million ha forest planning district located in south-central Labrador $\left(53^{\circ} 19^{\prime}\right.$ $\mathrm{N}, 60^{\circ} 25^{\prime} \mathrm{W}$; Fig. 3a). The district straddles an ecotone between high boreal and taiga ecosystems and contains most of Labrador's closed-canopy forests, dominated by black spruce (Picea mariana) and balsam fir (Abies balsamea) (Forsythe et al. 2003). Spruce-fir stands are embedded within a diverse mosaic of open sphagnum forest, lichen woodlands, mixed hardwoods (Betula spp., Populus spp.), black spruce bogs, lakes, and open wetlands. Fire is the dominant natural disturbance; although fire is less prevalent than in more continental regions further south and west (Simard 1973). Commercial harvesting in this district was limited to a few thousand hectares harvested between 1970 and the present day, and the district contains correspondingly few roads. The region is currently under treaty negotiations regarding land title and aboriginal rights between the Innu Nation and the Canadian and provincial governments. The largest communities in the region are Happy Valley - Goose Bay with about 8000 inhabitants, and the Innu community of Sheshatshiu with about 1200 people (Fig. 3a). Two main items of concern to local indigenous and nonindigenous communities have been identified: sufficient timber supply to support a local mill and therefore boost the local economy, and the viability of a threatened woodland caribou (Rangifer tarandus caribou) population (Schaefer 1999, Schmelzer et al. 2004) important to the cultural wellbeing of the region. Nonetheless, the Innu believe it is the interconnections between all elements of the forest, including the people who achieve their livelihood there, that ultimately ensure forest sustainability.

In 2001, the provincial government formed a cooperative agreement with the Innu Nation to produce a forest management plan for District 19A (Forsyth et al. 2003). The planning process started with extensive public consultations (of both Innu and non-Innu communities) to ensure that key values of all stakeholders were protected, before determining the extent and location of forest harvesting. The plan balances social, economic, and ecological values by first establishing a socioecological network (sensu Kangas and Store 2002) of conservation reserves to protect critical stakeholder interests (e.g., caribou habitat, culturally important travel corridors, viewsheds, etc.) (Fig. 3b). Management areas slated for timber harvesting are set within the remaining land area. The network of reserves is the broadest scale of conservation, but further conservation constraints are planned at the watershed and stand spatial scales. Despite the 5-year effort devoted to the development of the current plan, planners recognized several key areas where modeling could assist with decision making. These included a formal timber supply analysis, exploration of novel silvicultural systems, evaluation of alternative scenarios with different harvest rates or spatial patterning of cuts, more concrete projections of timber harvest impacts on caribou and other key stakeholder interests, and evaluation of how these different scenarios and their tradeoffs would be accepted by the local communities.

\section{Conceptual Model}

The team leader was reviewing dynamic forest models applicable to boreal systems (Messier et al. 2003) at the time the District 19A plan was developed and was invited to participate in the above planning process. Questions and issues raised suggested a suite of modeling tools that could improve planning in the district (Table 1, Appendix), and the application of those tools across Canada and other boreal systems (Fig. 1) suggested candidate team members. The final team included scientists with modeling and field expertise in: forest ecology at stand and landscape scales, habitat suitability and wildlife population dynamics, timber supply analyses, forest harvest optimization methods, forest economics, social science, and participatory modeling. Among the team members was a local scientist (N. Simon) who served as a key information conduit between the Labrador participants (stakeholders, planners, and domain experts) and the modeling team.

The formal conceptual model for Labrador planning District 19a included forest succession, tree seed dispersal, fire disturbance, timber supply, silvicultural practices, road building, and harvest patterns within the interactive model system (Fig. 4). Local stakeholders are interested in economic development, but rely heavily on the forests for a variety of non-timber values. We based our indicators on information gleaned from the public consultations of the planning process and through our own surveys and interviews (Berninger et al., 
Fig. 3. a) Forest Management District 19A (Labrador, Canada) straddles a major ecotone between boreal (closed canopy) and taiga (open canopy) systems, and serves as the test case for our toolkit approach. b) The socioecological conservation network outlined in the 20-year forest plan accounts for both ecological and cultural reserves, as well as connecting corridors. Fine-scale forest retention is also planned as estimated here.

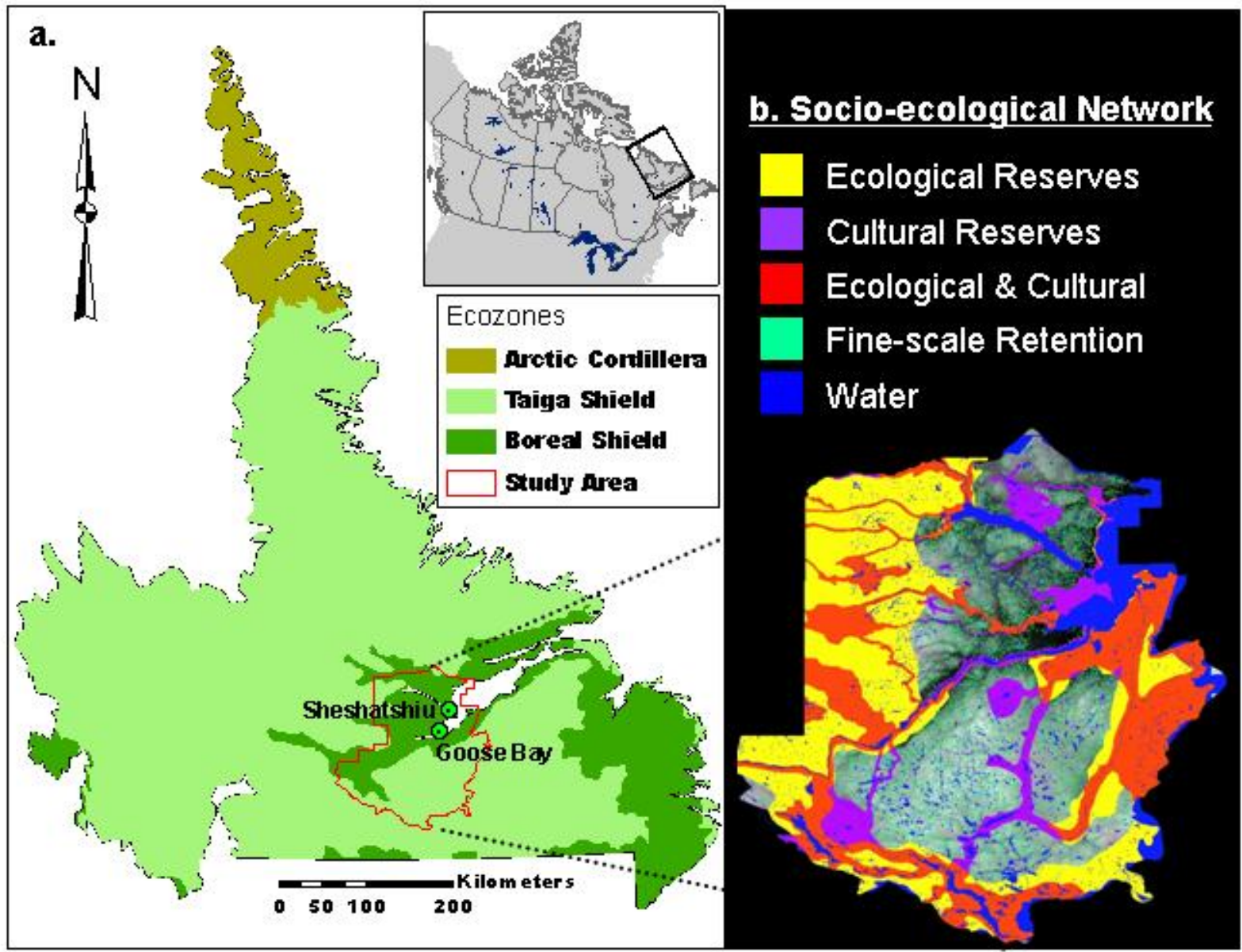

unpublished manuscript), including social, economic, and ecological dimensions (Fig. 4, Table 2). Human activities were conceptualized as controls implemented through alternative management scenarios, including the current forest management plan contrasted against unrestricted harvesting (i.e., no plan), a "no harvest" scenario, and an alternative to the plan that emphasized larger patch sizes for both cut-blocks and residual forest.

\section{Implemented Meta-model}

The modeling team first organized the available data resources (with the help of local domain experts) and modeling tools applicable to Labrador, creating a standardized data repository and a working document summarizing the models and their required inputs (http://www.lfmi.uqam.ca/home.htm ). Among the tools is SELES (Spatially Explicit Landscape Event Simulator; Fall and Fall 2001), a 
Table 1. Brief descriptions for specific modeling tools applied to the Labrador case study (Figure 5). More details, modeling examples, and links to supporting information are in the Appendix.

\begin{tabular}{ll}
\hline \hline Model Name & Brief description \\
\hline SELES & $\begin{array}{l}\text { A general tool for building grid-based models } \\
\text { of landscape dynamics (Fall and Fall 2001). }\end{array}$ \\
LINKAGES & $\begin{array}{l}\text { A forest ecosystem "gap" model that } \\
\text { simulates tree establishment and succession } \\
\text { as a function of soil water, nutrient dynamics, } \\
\text { and climate (Post and Pastor 1996). }\end{array}$ \\
$\begin{array}{l}\text { Canadian Forest Fire } \\
\text { Behavior Prediction } \\
\text { (FBP) }\end{array}$ & $\begin{array}{l}\text { An empirical model used to predict fire } \\
\text { spread rates and behavior based on fuel types, } \\
\text { weather, topography, and geographic location } \\
\text { (Forestry Canada Fire Danger Group 1992). }\end{array}$ \\
LANDIS-II & $\begin{array}{l}\text { A raster-based, landscape-scale disturbance } \\
\text { and succession model that trades mechanistic } \\
\text { detail for the ability to simulate over large } \\
\text { landscapes and long time scales (Mladenoff } \\
\text { 2004). }\end{array}$
\end{tabular}

SORTIE

Patchworks

Real Options

BAP toolbox
A spatially explicit, individual-tree, neighborhood-scale model that simulates stand development as an outcome of interactions among trees (Pacala et al. 1996).

A tool for producing spatial harvest schedules (http://www.spatial.ca/products/index.html )

A numerical analysis approach used in economics to inform decisions with irreversible consequences that affect a real asset (Dixit and Pindyck 1994).

A set of indicator models for assessing alternative management strategies in terms of biodiversity values (Doyon and Duinker 2003)
Role in Labrador District 19A meta-model

Parameterize relative fire spread rates within

Implement the 20-year plan, perform simulation-based timber supply analysis (D19aLM), and facilitate inter-model communication.

Estimate the probability of tree species establishment in LANDIS-II.

different forest cover types for use in landscape disturbance models (e.g., LANDIS-II).

Explore interactions between management and natural disturbance in terms of impacts on likely tree species and age patterns and composition.

Capture fine-scale succession processes to estimate changes in tree species composition and explore dynamics of partial harvesting regimes.

Produce harvest schedules, and compare with scenario-based approaches to timber supply analysis.

Explore economic aspects of planning, such as the decision to stop timber harvesting when it may trigger the extirpation of resident caribou (Morgan et al, unpublished).

Assess the consequences of different management scenarios on biodiversity using both coarse- and fine-filter approaches. general tool for building spatio-temporal models. SELES is our "glue" that links the assembly of models together by providing building blocks for landscape models and serving as translation engines for the transfer of data between models with different architecture (Table 1, Appendix).

The design of the Labrador District 19A metamodel (Fig. 5), along with some examples of results and links among models (Appendix), illustrates how meta-modeling can rapidly adapt existing models to specific SFM planning needs (See Table 1 and the Appendix for model descriptions). The District 19A landscape model (D19aLM), implemented in SELES, was designed initially as a spatially explicit timber supply model using growth and yield data provided from the province to forecast landscapescale sustainable harvest levels under a range of 
Table 2. Examples of indicators to be used in the Labrador test case, derived from local consultation sessions led by members of the modeling team, including justification for the criteria they indicate. Many indicators are modeled in the ecological realm, but their justification may come from the social realm.

\begin{tabular}{llc}
\hline \hline Indicator & Criteria \\
\cline { 2 - 3 } & Biodiversity & Ecosystem integrity Traditional activities Community well- \\
being
\end{tabular}

Ecological Realm

Aegolius funereus (boreal owl)

Martes americana (American marten)

Rangifer rangifer (caribou)

Age-class structure

Old forest in different forest types Coarse filter

Ecosystem diversity

Edge contrast and length

Habitat patch size/core area

Insular habitat connectivity

Fruit-bearing shrubs

\section{$\underline{\text { Social Realm }}$}

Number of forest-sector jobs

Landscape aesthetic sensitivity

Economic Realm

Harvest flow

Road length

Stumpage fees

Product costs

Planning costs risk
Species at risk

Indicator species

Species at risk

Ecosystem pattern

Ecosystem pattern

Ecosystem pattern

Landscape pattern

Landscape pattern

Landscape pattern

Berry harvesting

Local employment

Camping Ecotourism

Local employment

Increased poaching
Forest access

Forest access

Provincial revenue

Local profit

Reduced revenue 
Fig. 4. The formal conceptual model for Labrador planning district 19a meta-model. Key processes and their interactions are simulated within the interactive model system, which outputs information to be translated into key indicators of sustainability reflecting different values. Alternative management scenarios act on the model system through the subset of the processes humans influence; the relative success of those scenarios is quantified by the indicators.

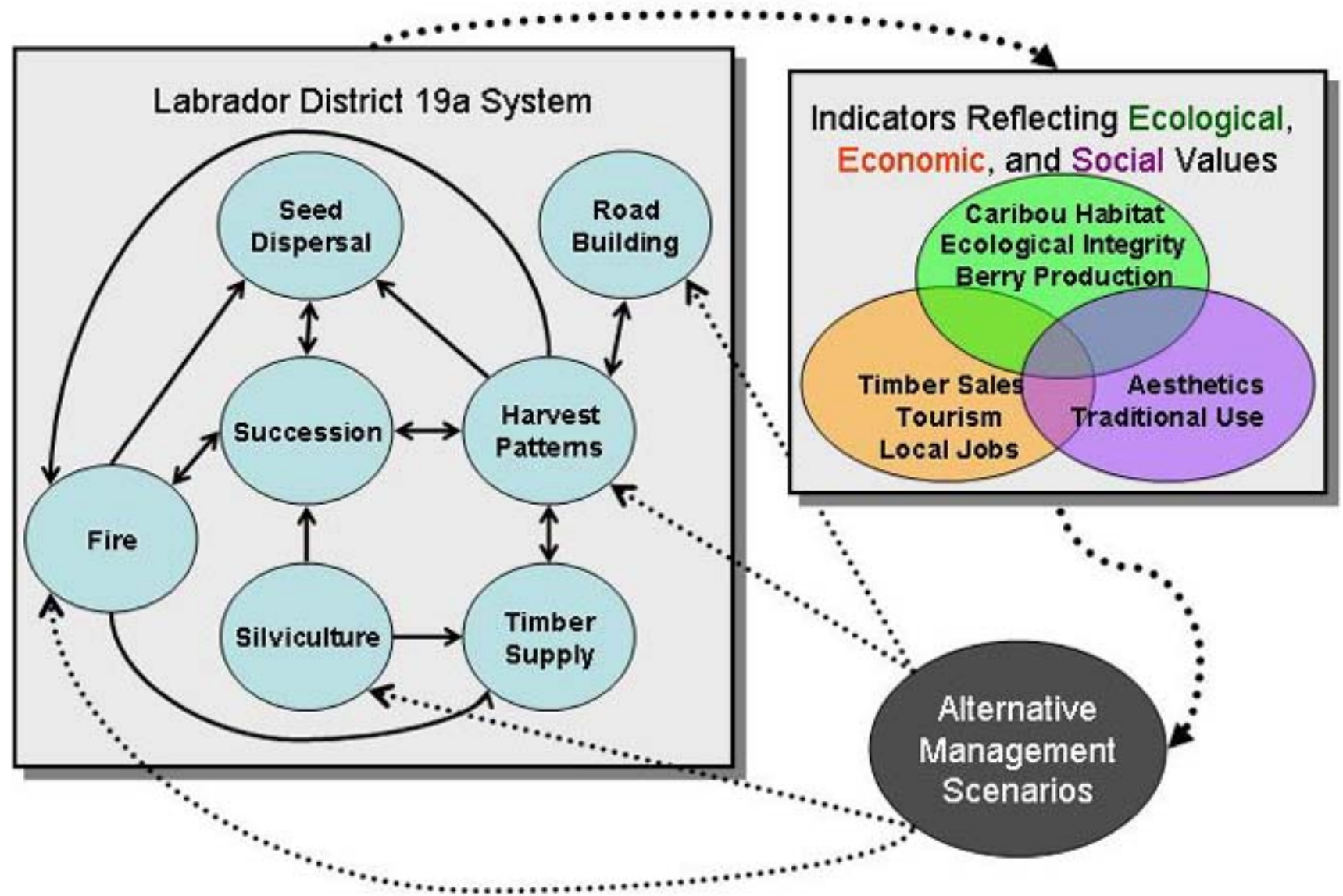

scenarios relevant to the current 20-year plan. Explorations of the fire regime using LANDIS-II, informed by fuel-specific fire spread rates from the Canadian forest fire behavior prediction (FBP) system, will be used to help integrate a simplistic forest succession into the D19aLM and inform the current empirical fire module. Results from individual tree modeling using SORTIE will be used to define more complex succession trajectories and yield curves in response to alternative silvicultural treatments. Results from spatial optimization of harvest schedules using Patchworks will be contrasted with the simulation-based timber supply approach used in the D19aLM to better understand how succession and fire disturbance affect harvest scheduling, economic return, and forest patterns. Output from some scenarios of the D19aLM have been used for economic analysis of caribou / timber harvesting interactions using a method known as "real options" (Morgan et al. unpublished). 
Ecological indicator models from the Biodiversity Assessment Project (BAP) toolbox are being adapted from application in western Newfoundland to the District 19a study area, and use both landscape-scale outputs from D19aLM and standscale outputs from SORTIE (Fig. 5).

\section{Iterative Learning and Model Refinement}

Modeling activity for the District 19A meta-model (Fig. 5) has focused on some components, yet this activity has still assisted mutual learning at all levels of participation (Fig. 2). For example, application of an economic tool (i.e., real options) to output from an ecological tool (D19aLM) facilitated interdisciplinary learning within the modeling team (i.e., the inner feedback loop of Fig. 2). A review of LANDIS output by local foresters (middle feedback loop, Fig. 2) identified soil conditions as a key driver of succession, specifically as it affects the establishment of balsam fir. In turn the foresters received formal training in spatial timber supply analyses using the current D19aLM. Preliminary output from a prototype D19aLM illustrating three main scenarios (no plan, current plan, and an alternative plan emphasizing larger cut-blocks) was shown to various stakeholder groups (outer feedback loop, Fig. 2). Participants were then asked if they had learned something or changed their opinions on forestry issues during the session (Fig. 6). Several participants had greater confidence in the current plan after viewing the forest projections. An important take-home lesson for the communities was that smaller cut blocks, or a network of small protected areas, require more roads to cut the same amount of wood. Thus, some were ready to accept bigger cut blocks and others were left with a desire to learn more. However, a key point raised by stakeholders was that forest roads do not last forever, and therefore, road accumulation may have been overestimated - these and similar comments were used to refine the model.

\section{LESSONS LEARNED}

In many respects the SFM toolkit approach is the same as any integrated modeling effort, thus previous experience and advice on communication across disciplines (Côté et al. 2001, Kinzig 2001, Bradshaw and Bekoff 2001, Lele and Norgaard
2005) and working as part of integrated teams (Nicolson et al. 2002) all apply. The key difference lies in the assembly of models designed for different purposes into a cohesive system that collectively informs the SFM planning process. This difference poses both unique opportunities and unique challenges to the modeling team. Chief among the advantages is that the cumulative science and experience underlying currently available models can be brought to bear on a specific planning initiative (in our case the D19A Forest Management plan). A primary challenge is the complexity associated with coupling models designed for different domains (see Appendix). The scientific advantages of the approach can be realized as long as the strengths and limitations of the tools are well understood (especially when the number of tools is large), and careful attention is paid to the pipelining strategies used to transfer information from one tool to the next.

A perpetual challenge during the assembly of the meta-model is finding the right balance between reuse or adaptation of existing tools and creation of new ones. When using an existing tool, there is always a risk of a mismatch between the tool and the conceptual model. This risk must be weighed against the time required to create and evaluate (Rykiel 1996) a new custom tool. In our case, most tools were modified versions of pre-existing models. Modern programming practices, such as modular architecture (Maxwell and Costanza 1997, Groenwold and Sonnenschein 1998, Scheller et al. 2007), simplify adaptation of existing models. As a case in point, the interaction between succession, harvesting, and fire disturbance could be realistically simulated in LANDIS-II by creating a new fire extension, but retaining other model components that fit the conceptual model of the case study. Similarly, simulation support tools such as SELES will continue to make customized modeling and meta-model assembly easier and more accessible to a broader audience. In time we envision a more general SFM toolkit applicable to boreal systems that can expand as new tools are added, key parameter ranges are defined, new issues are addressed, and new insights are gained from both individual and comparative modeling initiatives in the region.

The modular architecture of a meta-model allows progress to be made on multiple fronts simultaneously without waiting for results from the entire collection of models. We divided our team 
Fig. 5. Relationship diagram showing information flow between different models in the toolkit for the Labrador District 19A system, based on the conceptual diagram (Figure 4). Information exchange between models is organized in vertical (cross-scale) and horizontal (same scale) dimensions. Models are briefly summarized in Table 1, and online readers can click on a specific model "bubble" to access additional model detail and illustrations of information exchange from the Appendix.

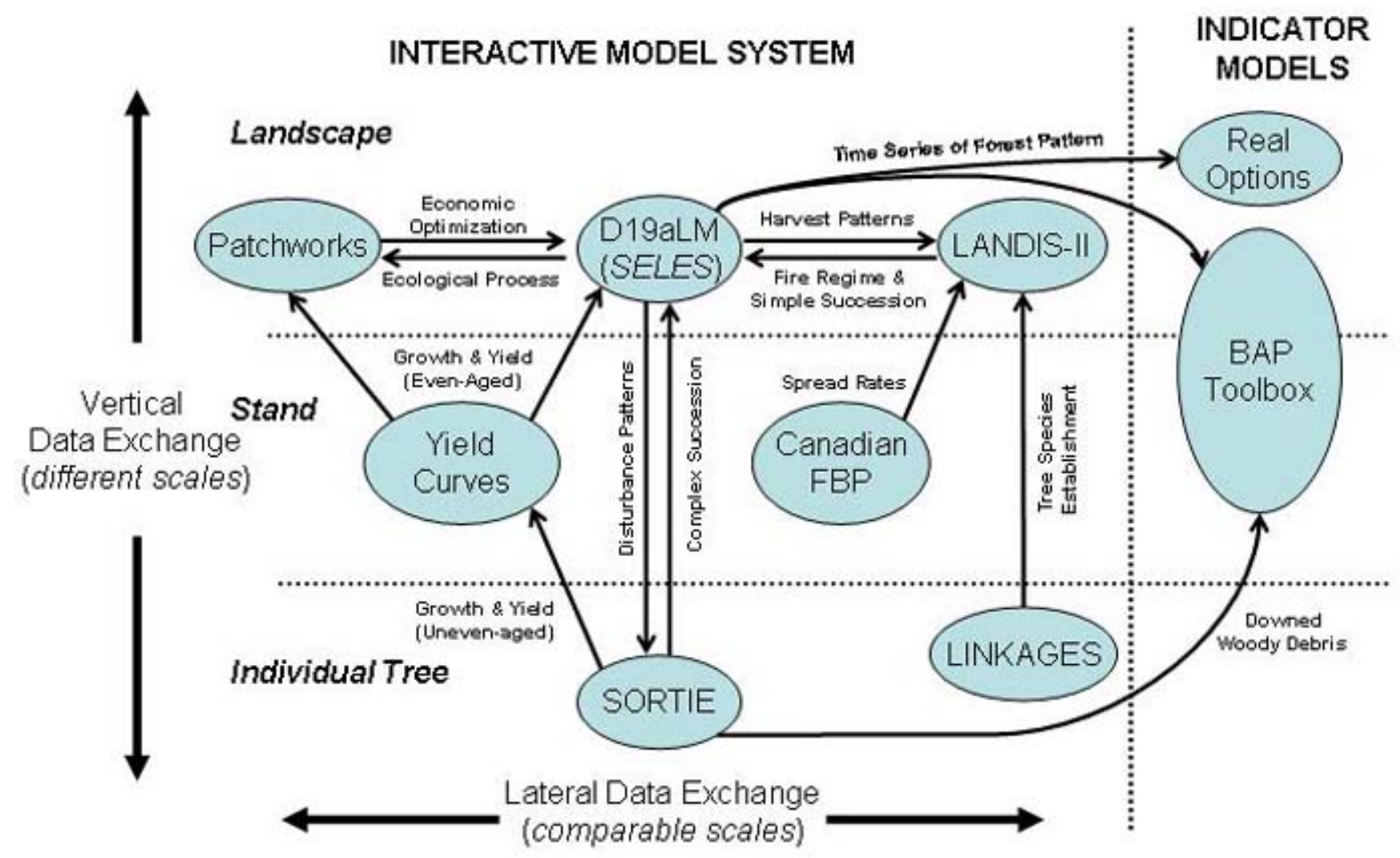

into working groups to make efficient use of effort, to ensure a set of elements that address project needs, and to focus attention on appropriate tools for each element. Preliminary, domain-specific modeling is an important form of prototyping that is essential for the iterative, two-way communication at all levels of participation (Fig. 2; Fall et al. 2001, Nicolson et al. 2002). However, there are inherent dependencies built into the modeling process (i.e., project definition, data identification, model selection, indicator development, etc.). If these dependencies are ignored, the process can easily degrade into an uncoordinated set of modeling exercises and the opportunity for true synthesis will be lost. Our experience suggests that strong leadership, in combination with a structured framework, is essential to the success of a toolkit approach. 
Fig. 6. Self evaluation by different stakeholder groups on learning and opinion change following discussion of simulation results of alternative management scenarios output by the Labrador District 19A Landscape Model (D19aLM).

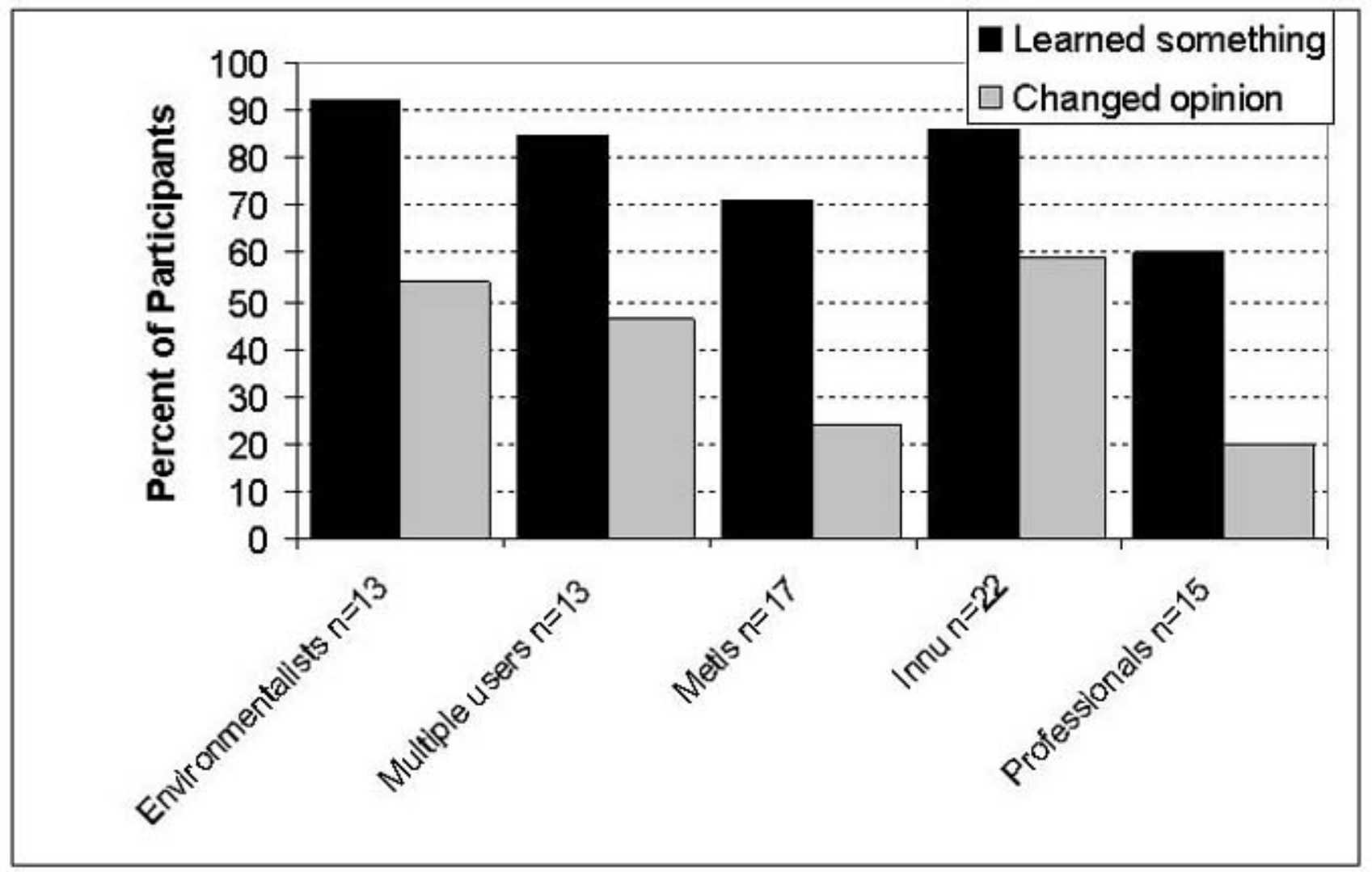

Team selection is critical when applying an SFM toolkit because the diversity of tools familiar to team members often defines the tools in the toolkit. Both off-the-shelf models and model-building software require knowledge, experience, and training before their use, and learning complex new tools may be at odds with project timelines. Thus, the team leader or leaders must ensure that the right team is assembled to meet a local SFM need. That is, to overcome the "chicken and egg" dilemma, where "until you define the problem, you cannot assemble a team; and until you have a team, you cannot really define the problem" (Nicholson et al. 2002, page 378 ), team leaders must go through a high-level iteration of the collaborative process and also have at least a cursory understanding of available modeling tools, as was our case in Labrador, before assembling the team. The conceptual model can then be refined by subsequent iterations with the newly assembled team. We also learned that including a local representative on the core modeling team vastly improved communications between the major groups (i.e., modelers, domain experts, planners, and stakeholders). 
The need for model transparency in participatory modeling initiatives is well recognized, but can also conflict with the use of research models designed for science rather than transparency. For example, Mendoza and Prabhu (2005, pages 146-147) suggest:

...for participatory modeling to be embraced at the local level, it must be configured in a form that is simple, transparent, and stripped of the typical complexity that often characterizes many models. The modeling paradigm must be such that stakeholders with little or no formal training in modeling can grasp the modeling process, feel comfortable in sharing their input and knowledge, and are able to contribute their expertise with relative ease.

Does this mean that published research models that are generally not transparent to the general public have no place in the collaborative modeling arena? Bypassing such models in favor of simplistic alternatives may restrict the flow of scientific knowledge into the planning process. A key to resolving this dilemma is effective two-way communication between the modeling team and the other participant groups at the appropriate time. For example, we found that stakeholder confidence in modeling results was greatly enhanced through frequent formal and informal communication with their experts. Therefore, the modeling team should work with local experts to ensure that they understand the strengths and weaknesses of tools applied to their domain. As domain experts often have their own tools, they may request model comparisons before they will begin to trust a new tool. Once satisfied that the implemented model is consistent with the formal conceptual model (Fig. 2), local experts can work with the modeling team to develop output that is accessible and easily understood by stakeholders.

Direct two-way communication with local stakeholders is also essential. In Labrador, longterm and large-spatial-scale comparisons of different management scenarios were shared with different stakeholder groups following meetings with outside experts organized by local domain experts. All parties gained important insights from this process (e.g., Fig. 6). Local stakeholders need to have their views heard, and discussed, and incorporated at several stages of the process. The scientists should make clear what the models are capable of doing and what may be unrealistic. This feedback is inherent in our hybrid approach of topdown and bottom-up flow of information through model analysis, workshops, and transparent discussion.

\section{CONCLUSIONS}

Any attempts to provide analytical support for SFM across different areas must recognize both the commonality and distinctiveness of issues and socioecological dynamics. Integrated models cannot be customized to fit every planning situation because there is a lack of capacity for building and applying complex spatio-temporal models. Conversely, no single model could adequately capture all systems and issues, especially as collaborative input from local stakeholders is important for plan acceptance. The toolkit approach has been developed in recognition of these constraints and opportunities, to use resources efficiently to minimize reinvention yet maximize innovation.

A toolkit approach to SFM analytical support is more about perspectives on information flow than on technical details. Certainly expertise and enabling technology are required to allow a team to apply such a framework. However, the essence of this approach is to seek balance between top-down (off the shelf, science-driven) and bottom-up (casespecific, stakeholder-driven) approaches to SFM decision support. We aim to find a pivot point, with adequate information flow from local experts and stakeholders to scientists, while at the same time avoiding "reinventing the wheel" (e.g., Fig. 1) by making full use of the cumulative experience of scientists and tools they have constructed. The mixture of local experts and stakeholders who understand how the tools work, scientists who are willing and able to communicate their science to stakeholders, and integrated analytical tools that can simulate complex spatial and temporal problems will provide powerful and efficient decision support for SFM. Bi-directional information flow between local experts, stakeholders, scientists, and planners is essential for efficient, timely, reliable, and adequate SFM meta-models. We have applied the toolkit process in Labrador, but fully recognize that this process will continue to evolve. Our proposal is not fully ripe, and certainly suffers from imperfections, but we believe the trend holds the best opportunity of meeting the challenges facing society regarding forest management. 
Responses to this article can be read online at:

http://www.ecologyandsociety.org/vol12/iss2/art7/responses/

\section{Acknowledgments:}

The SFM toolkit approach was funded under the Sustainable Forest Management Network of Canada. As a collaborative effort, there were many other funding sources, including the National Fire Plan of the U.S. Forest Service, the Centre d'Étude de la Forêt at the University of Quebec at Montreal, the Newfoundland and Labrador Department of Natural Resources, and the British Columbia Ministry of Forests. Robert Sutton completed the yield curves and Darren Jennings prepared GIS data for the Labrador case study; Keith Deering provided guidance on Labrador planning priorities. Brian Miranda assembled the fire weather inputs for the LANDIS-II simulations and assembled the LANDIS-II figures. Robert Scheller, Douglas Shinneman, and Brian Miranda helped design and implement the new LANDIS-II fire extension featured in the Labrador case study. We also thank Eric Gustafson, Dean Anderson, and three anonymous reviewers for valuable comments on the manuscript. We dedicate this paper in kind memory of Neal Simon, a great friend and colleague who passed away during the writing of the manuscript.

\section{LITERATURE CITED}

Aber, J. D., S. V. Ollinger, C. A. Federer, P. B. Reich, M. L. Goulden, D. W. Kicklighter, J. M. Melillo, and R. G. Lathrop, Jr. 1995. Predicting the effects of climate change on water yield and forest production in the northeastern United States. Climate Research 5:207-222.

Allen, T. F. H., and T. W. Hoekstra. 1992. Toward a unified ecology. Columbia University Press, New York, New York, USA.

Akçakaya, H. R. 2001. Linking population-level risk assessment with landscape and habitat models. Science of the Total Environment 274:283-291.

Antle, J. M., S. M. Capalbo, E. T. Elliott, W. Hunt, S. Mooney, and K. H. Paustian. 2001. Research needs for understanding and predicting the behavior of managed ecosystems: lessons from the study of agroecosystems. Ecosystems 4:723-735.

Baker, J. P., and D. H. Landers. 2004. Alternativefutures analysis for the Willamette River Basin, Oregon. Ecological Applications 14:311-312.

Bergeron, Y., B. Harvey, A. Leduc, and S. Gauthier. 1999. Forest management guidelines based on natural disturbance dynamics: stand- and forest-level considerations. The Forestry Chronicle 75:49-54.

Bradshaw, G. A., and M. Bekoff. 2001. Ecology and social responsibility: the re-embodiment of science. Trends in Ecology \& Evolution 16:460465.

Cissel, J.H., F. J. Swanson, W. A. McKee, and A. L. Burditt. 1994. Using the past to plan the future in the Pacific Northwest. Journal of Forestry 92:3031 .

Clarke, K. C. and L. J. Gaydos. 1998. Loosecoupling a cellular automaton model and GIS: longterm urban growth prediction for San Francisco and Washington/Baltimore. International Journal of Geographic Information Science 12:699-714.

Coates K. D., C. Messier, M. Beaudet, and C. D. Canham. 2003. SORTIE: a resource mediated, spatially explicit and individual-tree model that simulates stand dynamics in forest ecosystems. Forest Ecology and Management 186:297-310.

Commission d'étude sur la gestion de la forêt publique québécoise. 2004. Rapport. Québec, Québec, Canada.

Côté, M. A., and L. Bouthillier. 1999. Analysis of the relationship among stakeholders affected by sustainable forest management and forest certification. The Forestry Chronicle 75:961-966.

Côté. M. A., D. D. Kneeshaw, C. Messier, and L. Bouthillier. 2001. Increasing partnerships between scientists and forest managers. The Forestry Chronicle 77:85-89.

Derry, J. F. 1998. Modelling ecological interaction despite object-oriented modularity. Ecological Modelling 107:145-158.

Dixit, A., and R. Pindyck. 1994. Investment under uncertainty. Princeton University Press, Princeton, 
New Jersey, USA.

Doyon, F., and P. N. Duinker. 2003. Assessing forest-management strategies through the lens of biodiversity: a practical case from central-west Alberta. Pages 207-224 in G. J. Arthaud and T. M. Barrett, editors. Systems analysis in forest resources. Proceedings of the Eighth Symposium, Snowmass Village, Colorado, USA. Vol. 7, Managing Forest Ecosystems series, Kluwer Academic Publishers, Dordrecht, The Netherlands.

Fall, A., D. Daust, and D. G. Morgan. 2001. A framework and software tool to support collaborative landscape analysis: fitting square pegs into square holes. Transactions in GIS 5:67-86.

Fall, A., and J. Fall. 2001. A domain-specific language for models of landscape dynamics. Ecological Modelling 141:1-18.

Fall, A., M. J. Fortin, D. D. Kneeshaw, S. H. Yamasaki, C. Messier, L. Bouthillier, and S. Smyth. 2004. Consequences of various landscapescale ecosystem management strategies and fire cycles on age-class structure and harvest in boreal forests. Canadian Journal of Forest Research 34:310-322.

Feunekes, U., and A. Cogswell. 1997. A hierarchical approach to spatial forest planning. Pages ??? in Eds? Proceedings of the International Symposium on System Analysis and Management Decisions in Forestry. Traverse City, Michigan, USA.

Forestry Canada Fire Danger Group. 1992. Development and structure of the Canadian Forest Fire Behavior Prediction System. Forestry Canada, Science and Sustainable Development Directorate, Information Report ST-X-3, Ottawa, Ontario, Canada. (online.) URL: http://warehouse.pfc.forestry. ca/HQ/10068.pdf.

Forsyth, J., L. Innes, K. Deering, and L. Moores. 2003. Forest ecosystem strategy plan for Forest Management District 19 Labrador/Nitassinan. Innu Nation and Labrador Department of Forest Resources and Agrifoods. URL: http://www.env.gov. nl.ca/env/Env/EA\%202001/Project\%20Info/1062.htm

Groenwold, A., and M. Sonnenschein. 1998. Event-based modelling of ecological systems with asynchronous cellular automata. Ecological Modelling 108:37-52.

Grudin, J. 1991. Computer-supported cooperative work. Communications of the ACM 34:30-34.

Gunderson, L., and C. S. Holling, editors. 2002. Panarchy: understanding transformations in human and natural systems. Island Press, Washington, D. C., USA.

Gustafson, E. J., B. R. Sturtevant, and A. Fall. 2006. A collaborative, iterative approach to transfer modeling technology to land managers. Pages 123 134 in A. Perera, L. Buse, and T. Crow, editors. Forest landscape ecology: transferring knowledge to practice. Cambridge University Press, London, UK.

He, H. S., and D. J. Mladenoff. 1999. Spatially explicit and stochastic simulation of forestlandscape fire disturbance and succession. Ecology 80:81-99.

He, H. S., D. J. Mladenoff, and T. R. Crow. 1999. Linking an ecosystem model and a landscape model to study forest species response to climate warming. Ecological Modelling 114:213-233.

Holling, C. S. 1978. Adaptive environmental assessment and management. John Wiley, New York, New York, USA.

Hunter, M. L., Jr. 1990. Wildlife, forests and forestry. Principles for managing forests for biodiversity. Prentice Hall, Englewood Cliffs, New Jersey, USA.

Kangas, J., and R. Store. 2002. Socioecological landscape planning: an approach to multi-functional forest management. Silva Fennica 36:867-871.

Kimmins, J. P., D. Mailly, and B. Seely. 1999. Modelling forest ecosystem net primary production: the hybrid simulation approach used in FORECAST. Ecological Modelling 122:195-224.

Kinzig, A. P. 2001. Bridging disciplinary divides to address environmental and intellectual challenges. Ecosystems 4:701-715.

Kneeshaw, D. D., A. Leduc, C. Messier, P. Drapeau, D. Paré, S. Gauthier, R. Carignan, R. Doucet, and L. Bouthillier. 2000. Developing 
biophysical indicators of sustainable forest management at an operational scale. The Forestry Chronicle 76:482-493.

Kruse,J.A., R. G. White, H. E. Epstein, B.Archie, M. Berman, S. R. Braund, F. S. Chapin, J. Charlie, C. J. Daniel, J. Eamer, N. Flanders, B. Griffith, S. Haley, L. Huskey, B. Joseph, D. R. Klein, G. P. Kofinas, S. M Martin, S. M. Murphy, W. Nebesky, C. Nicolson, D. E. Russell, J. Tetlichi, A. Tussing, M. D. Walker, and O. R. Young. 2004. Modeling sustainability of arctic communities: an interdisciplinary collaboration of researchers and local knowledge holders. Ecosystems 7:815-828.

Lämås, T., and L. O. Eriksson. 2003. Analysis and planning systems for multiresource, sustainable forestry: the Heureka research programme at SLU. Canadian Journal of Forest Research 33:500-508.

Larson, M. A., F. R. Thompson, III, J. J. Millspaugh, W. D. Dijak, and S. R. Shifley. 2004. Linking population viability, habitat suitability, and landscape simulation models for conservation planning. Ecological Modelling 180:103-118.

Lele, S., and R. B. Norgaard. 2005. Practicing interdisciplinarity. Bioscience 55:967-975.

Lertzman, K., and J. Fall. 1998. From forest stands to landscapes: spatial scales and the roles of disturbances. Pages 339-368 in D. L. Peterson and V. T. Parker, editors. Ecological scale: theory and applications. Columbia University Press, New York, New York, USA.

Maxwell, T., and R. Costanza. 1997. A language for modular spatio-temporal simulation. Ecological Modelling 103:105-113.

Mendoza, G. A., and R. Prabhu. 2005. Combining participatory modeling and multi-criteria analysis for community-based forest management. Forest Ecology and Management 207(1-2):145-156.

Messier, C., M.- J. Fortin, F. Schmiegelow, F. Doyon, S. G. Cumming, J. P. Kimmins, B.,

Mladenoff, D. J. 2004. Landis and forest landscape models. Ecological Modelling 180:7-19.

Nicolson, C. R., A. M. Starfield, G. P. Kofinas, and J. A. Kruse. 2002. Ten heuristics for interdisciplinary modeling projects. Ecosystems
5:376-384

O'Neill, R. V., D. L. DeAngelis, J B. Waide, and T. F. H. Allen. 1986. A hierarchical concept of ecosystems. Monographs in Population Biology 23:1-272.

Orton, J. D., and K. E. Weick. 1990. Loosely coupled systems: a reconceptualization, Academy of Management Review 15:203-223.

Pacala, S. W., C. D. Canham, J. Saponara, J. A. Silander, Jr., R. K. Kobe, and E. Ribbens. 1996. Forest models defined by field measurements: estimation, error analysis, and dynamics. Ecological Monographs 66:1-43.

Pennanen, J., D. Greene, M.- J. Fortin, and C. Messier. 2004. Spatially explicit simulation of longterm boreal forest landscape dynamics with prediction of quantitative attributes. Ecological Modelling 180:195-209.

Peterson, G. D. 2002. Contagious disturbance, ecological memory, and the emergence of landscape pattern. Ecosystems 5:329-338.

Post, W. M., and J. Pastor. 1996. LINKAGESan individual-based forest ecosystem model. Climatic Change 34:253-261.

Province of British Columbia. 1996. Forestry Practices Code of British Columbia Act. Queen Printers, Victoria, British Columbia, Canada.

Rastetter, E. B. 2003. The collision of hypotheses: what can be learned by comparing models? Pages 211-224 in C. D. Canham, J. J. Cole, and W. K. Lauenroth, editors. Models in ecosystem science. Princeton University Press, Princeton, New Jersey, USA.

Rykiel, E. J., Jr. 1996. Testing ecological models: the meaning of validation. Ecological Modelling 90:229-244.

Salus, P. H. 1994. A quarter century of UNIX. Addision Wesley, Reading, Massachusetts, USA. ISBN 0-201-54777-5.

Schaefer, J.A. 1999. Demography of decline of the Red Wine Mountains caribou herd. Journal of Wildlife Management 63:580-587. 
Scheller, R. M., J. B. Domingo, B. R. Sturtevant, J. S. Williams, A. Rudy, E. J. Gustafson, and D. J. Mladenoff. 2007. Design, development, and application of LANDIS-II, a spatial landscape simulation model with flexible temporal and spatial resolution. Ecological Modelling 201:409-419.

Schmelzer, I., J. Brazil, T. Chubbs, S. French, B. Hearn, R. Jeffery, L. LeDrew, H. Martin, A. McNeill, R. Otto, F. Phillips, G. Mitchell, G. Pittmann, N. Simon, and G. Yetman. 2004. Recovery strategy for three woodland caribou herds (Rangifer tarandus caribou; boreal population) in Labrador, Canada. Department of Environment and Conservation, Government of Newfoundland and Labrador, Corner Brook, Newfoundland and Labrador, Canada.

Schulte, L. A., R. J. Mitchell, M. L. Hunter, Jr., J. F. Franklin, R. K. McIntyre, and B. J. Palik. 2006. Evaluating the conceptual tools for forest biodiversity conservation and their implementation in the U.S. Forest Ecology and Management 232:111 .

Simard, A. J. 1973. Forest fire weather zones of Canada. (Map with text.) Environment Canada, Canadian Forestry Service, Ottawa, Ontario, Canada.

Spies, T. A., W. J. Ripple, and G. A. Bradshaw. 1994. Dynamics and pattern of a managed coniferous forest landscape in Oregon. Ecological Applications 4:555-568.

Sturtevant, B. R., P. A. Zollner, E. J. Gustafson, and D. T. Cleland. 2004. Human influence on fuel connectivity and the risk of catastrophic fire in mixed forests of northern Wisconsin. Landscape Ecology 19:235-253.

Urban, D. L. 2005. Modeling ecological processes across scales. Ecology 86:1996-2006.

Urban, D. L., M. F. Acevedo, and S. L. Garman. 1999. Scaling fine-scale processes to large scale patterns using models derived from models: metamodels. Pages ??? in D. J. Mladenoff and W. L. Baker, editors. Advances in spatial modeling of forest landscape change: approaches and applications. Cambridge University Press, Cambridge, UK.

Williams M., E. B. Rastetter, D. N. Fernandes,
M. L. Goulden, G. R. Shaver, and L. C. Johnson. 1997. Predicting gross primary productivity in terrestrial ecosystems. Ecological Applications 7:882-894.

van Damme, L., J. Russell, F. Doyon, P. N. Duinker, T. Gooding, K. Hirsch, R. Rothwell, and A. Rudy. 2003. The development and application of decision support systems for sustainable forest management in Alberta. Journal of Environmental Engineering and Science 2:S23-S34. 
APPENDIX 1. Labrador District 19A toolkit \& meta-model overview.

Our team is assembling a meta-model to provide strategic guidance for sustainable forest management (SFM) in forest planning District 19A in Labrador. Here we overview the modeling "tools" that contribute the District 19A meta-model summarized briefly in Table 1. Each tool summary includes a brief illustration of how the tool contributes to the larger meta-model (Fig. 5). Following the iterative collaborative modeling approach to support SFM planning (Fall et al. 2001, Fig. 2), the meta-model presented here is a work in progress that will continue to be refined through repeated feedback from local domain experts, planners, and stakeholders.

\section{SELES}

SELES (Spatially Explicit Landscape Event Simulator; Fall and Fall 2001) is a raster-based tool for constructing, running and visualizing spatial landscape models that integrate natural and anthropogenic processes (e.g., fire, insects, logging, and succession). It can also perform spatial analysis (e.g., habitat connectivity), and track indicators (e.g., age class, habitat supply, growing stock) over long time-frames and large spatial areas. SELES is a research tool as well as a decision-support tool for problems related to conservation and resource management. It combines a declarative language for specifying spatial and spatio-temporal models, a text editor for creating or adapting and parsing models, and a simulation engine for running models and visualizing outputs. The SELES modeling language can be used to specify key landscape processes and link to other models such as SORTIE and LANDIS. SELES captures landscape dynamics using "landscape events" and "landscape agents." The former are used for processes that return to the landscape periodically, initiate in one or more locations, spread to adjacent areas, and cause some change to the state of the system. The latter are used to for individual-based models, where dynamic components retain their identity as they move around and change the landscape state. SELES uses a discreteevent simulation engine to process events or agents during a simulation, allowing for complex interactions to be captured. As a flexible modeling tool, SELES supports collaborative modeling frameworks (Fall et al. 2001), while the open nature of the language allows re-use and adaptation of model components from other projects. More information and a free downloadable version are available at http://www.gowlland.ca

\section{Fig. 5 D19aLM (SELES)}

The District 19a Landscape Model (D19aLM) is a forest dynamics model implemented in SELES. The underlying basis is a spatial forest estate model that captures stand aging and timber harvesting, and projects growing stock (based on input growth and yield information) and timber supply indicators such as volume harvested, mean age harvested, and roads built. The D19aLM was designed to support timber supply analysis, in which sustainable harvest levels are identified by sets of experimental simulations in which maximum sustainable levels are identified based on an ability to meet harvest targets, and on non-declining growing stock. The main components of the D19aLM are (i) stand aging, (ii) calculation of growing stock based on site type, stand age and growth and yield tables (Fig. A1a), (iii) a planning step that identifies stands available for harvest based on minimum harvest ages, road access, etc., (iv) harvesting, and (v) road building. The harvesting component selects available stands to start cutblocks, spreading out to adjacent available stands to reach a target block size (selected from an input distribution), and continuing to place blocks until either the harvest target for the time step is met or there are no more available stands (Fig. A1b). Selection preferences are controlled by parameters (e.g., increasing preference with age and decreasing preference with distance to nearest road). The road building component uses the mapped existing road network to constraint harvest access. As harvesting proceeds, road segments are created by adding segments to connect blocks to the current road network (Fig. A1b). The D19aLM "base model" includes an empirical fire model defined by fire rotation and size distribution parameters. This base model was designed for extension - for example it can support state-based tree species succession and more complex fire processes. The D19aLM was also designed to link with other models by producing spatial-temporal 
output (time sequences of spatial maps) that can be used as input to other models (e.g. indicators). To date the model has been used to contrast the road-building and timber supply consequences of the current 20 year plan in comparison with some simple alternatives (e.g., Fig. A1c), to elicit stakeholder feedback, and to train local foresters in spatial timber supply techniques in Labrador.
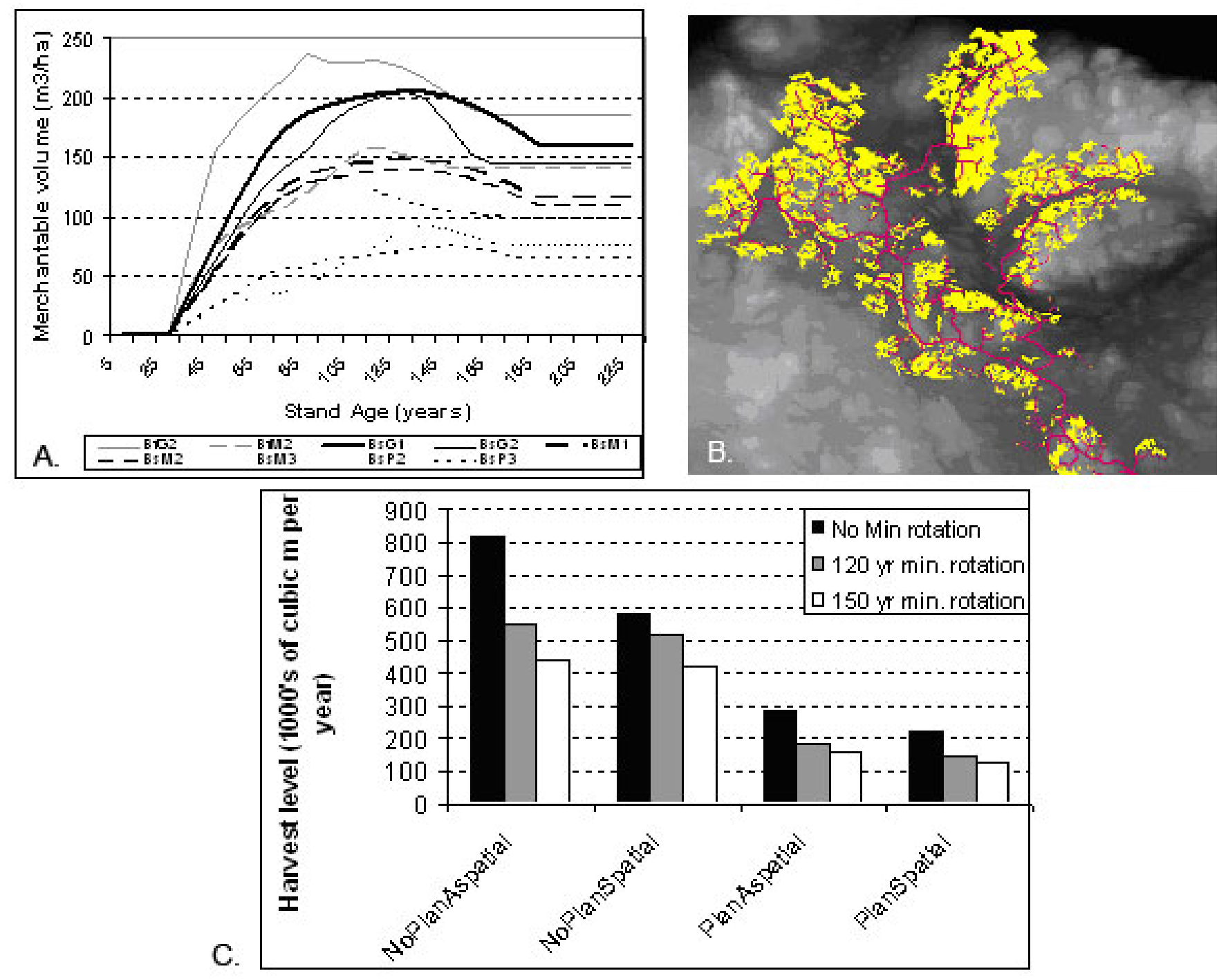

Figure A1. a. Empirical growth and yield curves for Labrador, used as input for the D19aLM model to project timber supply. Individual yield curves represent species and "site types" combinations for "high boreal" ecoregion, where the first two letters represent the species ( $\mathrm{Bf}=$ balsam fir; $\mathrm{Bs}=$ black spruce), the third letter is the site quality ( $\mathrm{G}=$ good; $\mathrm{M}=$ medium; $\mathrm{P}=$ poor), and the last number is the crown closure class $(1=>75 \% ; 2=51-75 \% ; 3=26-50 \%)$. b. Simulated forest "cutblocks" (yellow) dependent on an expanding road network (magenta), overlaid on a digital elevation model. c. D19aLM output showing maximum annual allowable cut in response to different combinations of constraints: No plan versus the 20-year plan (i.e., "Plan"); spatial constraints (i.e., within $2 \mathrm{~km}$ of roads, including new road placement) versus no spatial constraints on harvesting ("Aspatial"); no minimum rotation period versus 120 and 150 year minimum stand rotations. 


\section{Fig. 5 LINKAGES}

LINKAGES is an ecosystem process model that simulates individual tree establishment, growth, competition, and mortality as a function of soil water, nutrient dynamics, and monthly average temperature and precipitation (Post and Pastor 1996). The model is a direct descendent of the original forest gap models (Botkin et al. 1972, Shugart and West 1977). LINKAGES was used to estimate the probability of tree establishment for tree species in two different ecozones of the District 19A landscape that are defined primarily by elevation (i.e., high-boreal, sub-artic), following the methods of Scheller et al. (2005). Resulting species establishment probabilities (Table A1) were consistent with the experience of local foresters in Labrador. An exception was balsam fir (Abies balsamea), for which establishment was low relative to local expectations. The discrepancy was resolved when it became clear that balsam fir was sensitive to local soil conditions, i.e., likelihood of establishment should be less on poor-quality soils and greater on high-quality soils. A more detailed "land type" map based on stand-scale soil conditions will therefore improve the successional patterns observed in LANDIS-II (see LANDIS-II below). 
Table A1. Establishment probabilities required as input for LANDIS-II for eight tree species in Labrador planning District 19A, as estimated using LINKAGES, a forest gap-scaled ecosystem model. Discrepancies with the establishment probabilities for balsam fir (in bold) identified by provincial foresters led to recognition that finer-scaled soils data are required to accurately simulate successional trends in LANDISII.

Ecozone

Tree Species 


\section{Fig. 5 Canadian FBP}

The Canadian Forest Fire Behavior Prediction (FBP) System uses data from both experimental fires and wildfires across Canada to provide quantitative estimates of potential head fire spread rate, fuel consumption, and fire intensity, as well as qualitative descriptions of forest fire behavior (e.g. surface fire, crown fire) (Forestry Canada Fire Danger Group 1992). Key inputs include fuel type, weather, topography, and foliar moisture content (typically estimated using geographic location). The system is often combined with an elliptical fire growth model to provide tactical support for fire-fighting personnel. More information on the Canadian FBP can be found at http://cwfis.cfs.nrcan.gc.ca/en/background/ bi FBP summary e.php. Fire disturbance and fuel extensions based on the Canadian FBP were implemented in LANDIS-II (Fig. A2) to investigate interactions between fire, harvesting, and succession in Labrador District 19A (see LANDIS-II below).
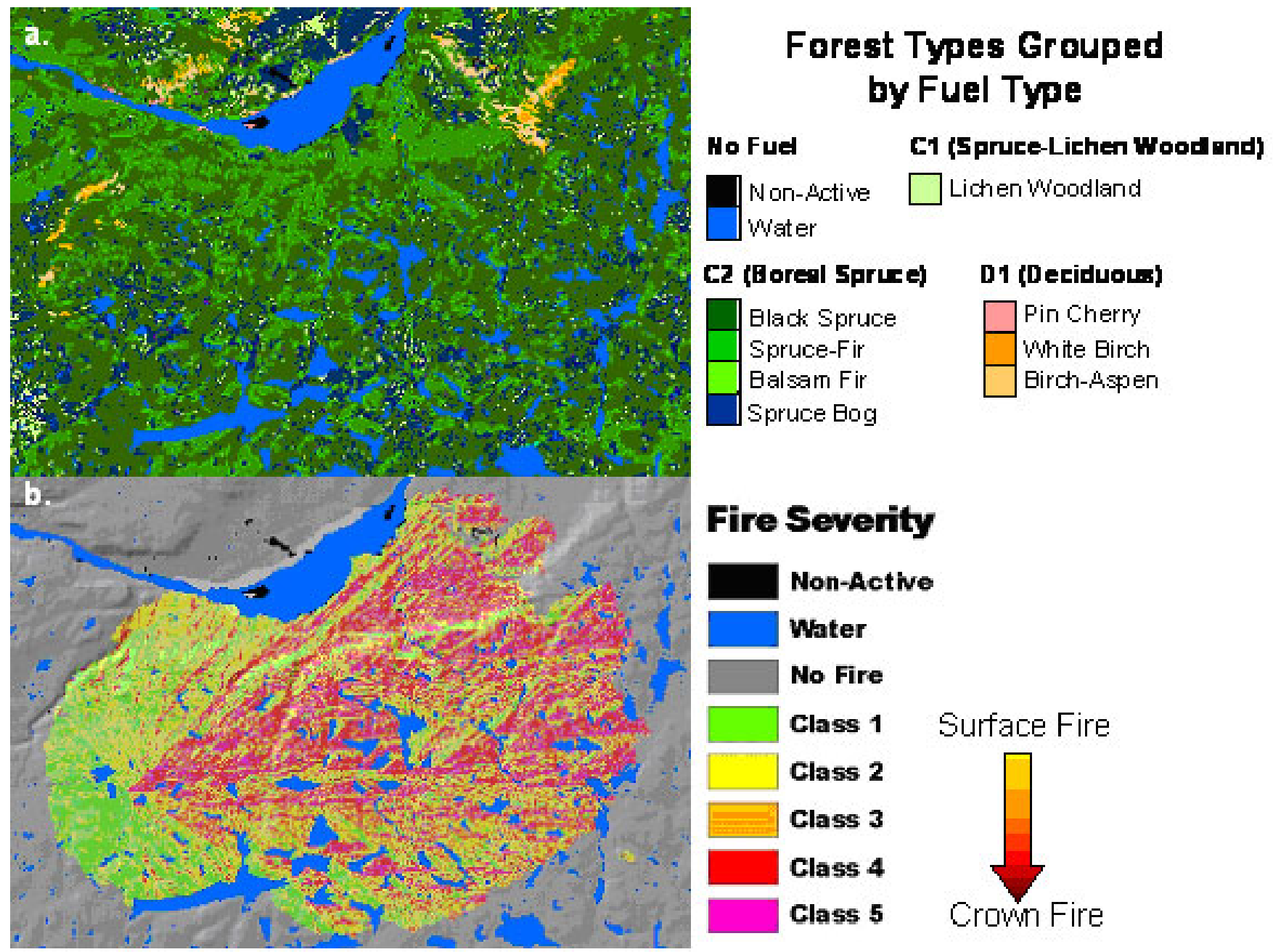

\section{Fire Severity}

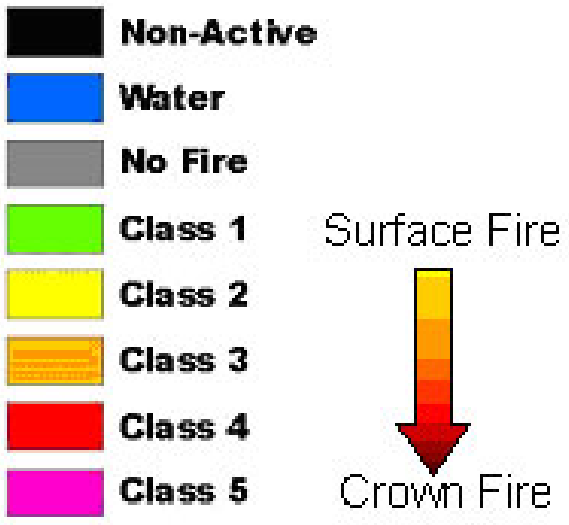

Figure A2. a. Forest cover types from LANDIS-II translated into fuel types the Canadian Forest Fire Behavior Prediction (FBP) System. b. A simulated fire event and resulting fire severity pattern responding to the landscape configuration of fuel types, using fire spread equations from the Canadian FBP. 


\section{Fig. 5 LANDIS-II}

LANDIS-II (Scheller et al. 2007; http://landis.forest.wisc.edu) is a recent elaboration of previous LANDIS models (from LANDscape DIsturbance and Succession; Mladenoff et al. 1996). LANDIS models in general simulate broad-scale $\left(>10^{5} \mathrm{ha}\right)$ landscape dynamics, including succession, disturbance, seed dispersal, forest management, and climate change effects (Mladenoff 2004). Landscapes are represented as a grid of interacting cells with user-defined spatial resolution (cell size) generally ranging from 0.1 ha - 100 ha in size. Individual cells have homogeneous light environments, and are aggregated into ecoregions with homogeneous climate and soils. Forest composition at the cell level is represented as age cohorts of individual tree species that interact via a suite of vital attributes (i. e., shade tolerance, fire tolerance, seed dispersal, ability to sprout vegetatively, and longevity) to produce nondeterministic successional pathways sensitive to disturbance type and severity. LANDIS-II was re-engineered as an integrated modeling environment that allows the creation of custom forest landscape disturbance and succession extensions while maintaining and building upon the scientific rigor of the original LANDIS model (Scheller et al. 2007). Strengths of LANDIS-II include the new flexibility introduced through multiple inter-woven time steps, a library of published succession and disturbance extensions (He and Mladenoff 1999, Gustafson et al. 2000, Sturtevant et al. 2004), and the optional integration of additional cohort data and biomass dynamics (Scheller and Mladenoff 2004).

We are using LANDIS-II to investigate the strength of interactions between forest succession, harvesting, and fire disturbance processes (Simon et al. 2006), using both functions and input from other models in the toolkit. For example, the harvest module of LANDIS-II was designed for managed landscapes of the United States where abundant roads rarely limit harvest patterns (Gustafson et al. 2000), an assumption that did not capture the road-limited harvest pattern of Labrador well. We circumvented this limitation by parameterized the existing harvest extension to match the harvest patterns output by the D19aLM. In contrast, new fire disturbance and fuel extensions were created in LANDIS-II based on the Canadian FBP. The fuel extension translates the species age-list present on each cell into one of the 17 Canadian fuel types using a look-up table (Fig. A2a). We applied a durationbased approach to simulate the Labrador fire regime, where a fire duration distribution was calibrated to generate the fire size distribution observed in regional fire records, and fire duration for a given event was then selected from the calibrated distribution (Penannen and Kuuluvainen 2002). This approach allows the fire regime to change in response to changing fuel conditions and patterns (Didion et al. 2007). Fires spread to adjacent cells at rates defined by the fire event weather, wind direction, and fuel type based on the rate functions defined by the Canadian FBP (Forestry Canada Fire Danger Group 1992; Fig. A2b). Fire severity is a based on the estimated crown fraction burned; a fuel-specific function of the fire spread rates (Forestry Canada Fire Danger Group 1992). Species composition changes in response to fire and harvest (Fig. A3) that in turn influence the fire regime by modifying landscape fuel patterns.

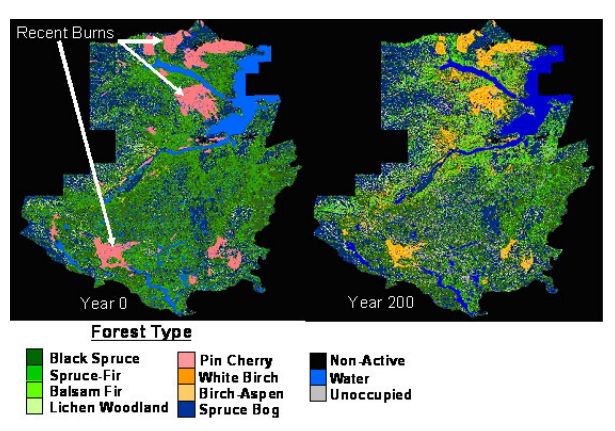


Figure A3. a. Initial forest composition in Labrador's forest planning District 19a; b. LANDIS-II projection of forest condition following 200 years of succession in response to fire and harvest (no plan scenario).

\section{Fig. 5 SORTIE}

SORTIE is an individual-tree model of forest dynamics at the stand scale originally developed for hardwood forests in the northeastern US to forecast long-term changes in the abundance and spatial distribution of tree species as a function of the competitive dynamics of individuals in a stand (Pacala et al., 1993, 1996). The model has since been adapted to study the effects on forest dynamics of spatial patterns of forest management (Beaudet et al. 2002, Coates et al. 2003), wind storms (Papaik and Canham 2006a, Uriarte and Papaik in press) and pathogens (Papaik et al. 2005). It uses empirically supported relationships in four basic submodels: seedling recruitment, light availability, growth, and mortality, as well as submodels for disturbance that include: wind, biotic agents, and harvest. The harvest submodel can simulate any type of silvicultural strategy that removes or retains trees by species, size and location. Thus, SORTIE is a flexible and well-tested complex stand model that can be used to support a wide range of SFM applications.

SORTIE has recently been re-engineered as a general neighborhood dynamics model that can incorporate variation in ecosystem characteristics and disturbance (SORTIE-ND). SORTIE-ND is a scalable model that has been designed to quickly incorporate key site specific relationships across a region to improve inferences above the stand scale. For our Labrador case study, field efforts first targeted data required to estimate juvenile and adult tree growth functions for use with growth and yield models as these are the most important submodels for estimating the short-term effects of silviculture on stand dynamics. SORTIE will allow us to "scale-up" the alternative silviculture treatments to the landscape to help address some scaling issues confronting forest management. More information on the SORTIE-ND model can be found at http://www.sortie-nd.org).

\section{Fig. 5 Patchworks}

Patchworks (Spatial Planning Systems, Inc) is a spatially explicit harvest scheduling model that uses optimization techniques to analyze trade-offs between competing sustainability goals (Lockwood and Moore 1993). Different objectives such as timber supply, habitat and old-growth retention, and patch distributions are evaluated with user-defined weighting factors that rank the importance and contribution of each factor into a multi-objective function. This design allows planners to explore the interactions between stakeholder interests in order to derive a trade-off function. Patchworks integrates operationalscale decision-making within a strategic-analysis environment, such that spatially explicit harvest allocations can be developed over different planning horizons, compatible with 5-year and 20-year operational plans as well as long-term sustainability. The model is fully integrated with an interactive GIS interface. The real-time, interactive nature of the Patchworks model allows planners to visualize solutions over time, and to test the abilities of management actions to achieve a range of management goals. A variety of realistic long-term spatial allocation criteria can be applied simultaneously, such as patch size targets, adjacency constraints, sub-regional targets, zonal constraints (e.g. landscape management, visual quality objectives). Patchworks is used in this project to assess optimal solutions of multi-objective forest management problems in order to derive trade-off functions between stakeholder interests. Forest dynamics from stand-level models are summarized in the form of yield tables for input to Patchworks (e.g., volume of merchantable timber, number of snags). The harvest schedules output from Patchworks can be used as input to indicator models or to guide logging in the D19aLM. More information on the Patchworks model can be found at http://www.spatial.ca/products/index.html. 
Real options is an analysis method used for financial decision making that considers risk and uncertainty (Dixit and Pindyck 1994). A real option is characterized as "the value of being able to choose some characteristic (e.g., the timing) of a decision with irreversible consequences, which affects a real asset (as opposed to a financial asset)" (Saphores and Carr 2000). Under real options, problems are formulated so that they can be solved by numerical methods. We applied this technique to the problem of the negative impacts that timber harvesting may have on the viability of a woodland caribou (Rangifer tarandus caribou) population (Morgan et al. unpublished). Wildfire, forest harvesting, and forest age were used as the defining processes of the system. These processes were modeled using the D19aLM to estimate the amount and variability of old forest over time. To apply the real options methodology, these estimates were used to represent the expected supply and variability of caribou habitat using a mean-reverting numerical equation (Dixit and Pindyck 1994) Fig. A4). Included in the formulation is a stopping rule, which in our case reflects the timing of closing down harvesting when the amount of caribou habitat approaches a critical threshold. The rule represents the trade-off between maintaining an adequate amount of habitat to ensure the survival of the caribou, and providing socioeconomic opportunity by harvesting timber. The timing is sensitive to the level of risk that society is willing to tolerate and the amount of uncertainty associated with the system, such as, long term natural disturbance or how caribou population dynamics would be impacted by commercial forestry activities.

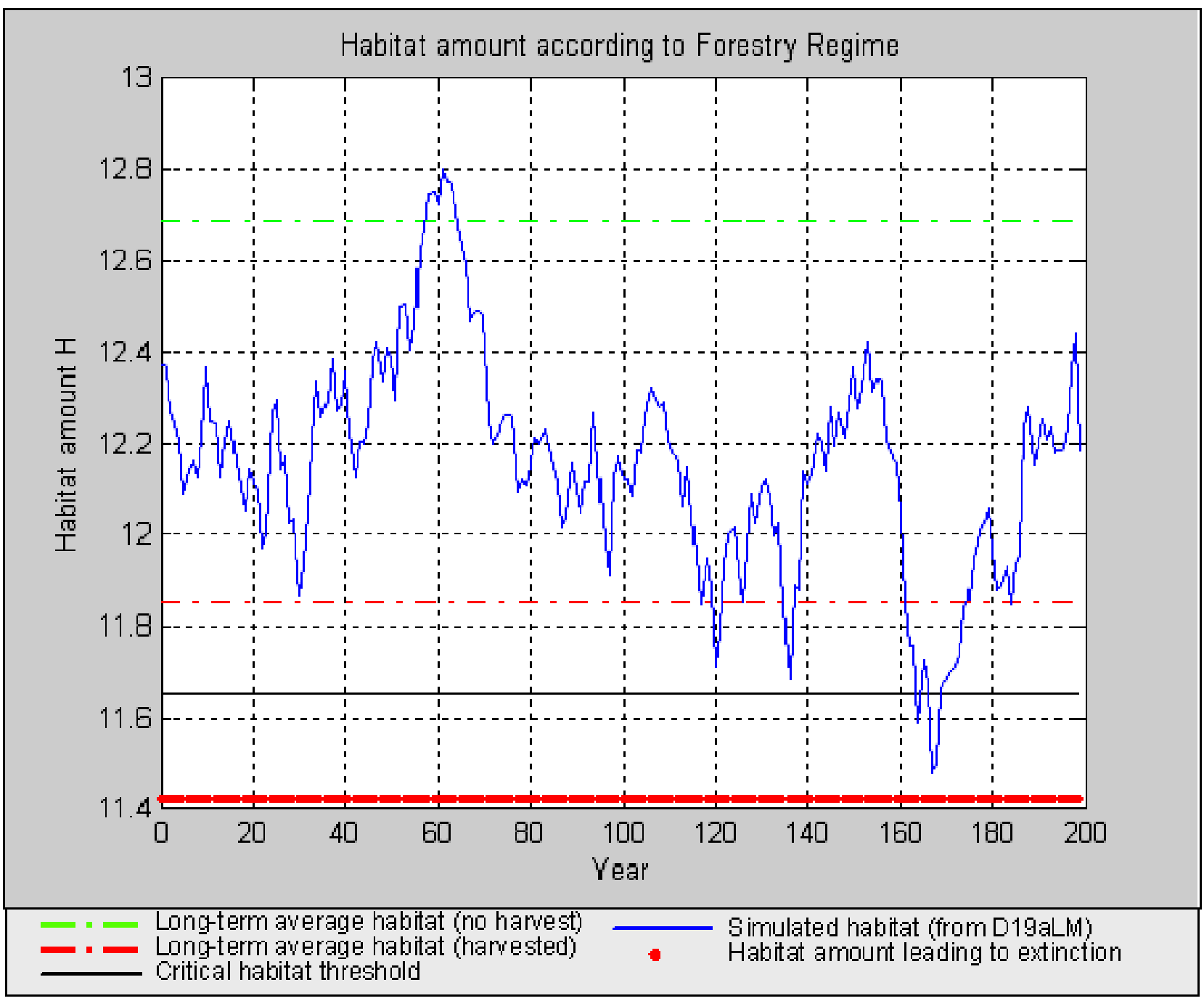


Figure A4. Example of the amount H (i.e., the natural log of caribou habitat in hectares, over 200 years) where the supply of habitat falls below a critical threshold of minimum habitat after 160 years of landscape dynamics, including forest growth, harvesting and fire (Morgan et al. unpublished).

\section{Fig. 5 BAP Toolbox}

The Biodiversity Assessment Project (BAP) toolbox is a suite of indicator models used to assess diverse forest management strategies at three levels of biodiversity: landscape patterns, ecosystem diversity, and habitat supply for specific vertebrate species (Doyon and Duinker 2003). The approach was inspired by the coarse- and fine-filter approach from conservation biology (Hunter 1990) where landscape pattern and ecosystem diversity indicators serve as coarse filters while habitat supply models (HSMs) serve as fine filters. The BAP Toolbox translates a time series of landscape conditions output from landscape models (e.g., D19aLM) into habitat types that serve as spatial units for ecosystem and the landscape biodiversity (i.e., coarse-filter) assessment. The HSMs are based on up-to-date literature on the wildlife species, where the envirogram technique (Andrewartha and Birch 1984), proposed by Van Horne and Wiens (1991), is used to conceptualize the models. Habitat suitability is defined using stand-level habitat elements (including the spatial arrangement of elements) required for species crucial life activities. Many of these stand-level habitat elements such as snags, downed woody debris or understory vegetation are typically not available as output from forest projection tools or standard forest inventory. In these cases the BAP Toolbox uses Stand-level Habitat Element (SHE) models to characterize their changes through forest succession, vegetation manipulation, and disturbances based on empirical relationships between different forest conditions (e.g., forest age) and the habitat elements. In the Labrador case study, some SHE models will be replaced by output from SORTIE to address element responses to novel silvicultural treatments.

The BAP Toolbox is coded into the Arc-GIS environment (ESRI Inc.) and each of the three levels of biodiversity forms an independent analytical module that can be parameterized to express the regional forest conditions. The BAP Toolbox also includes some analysis and interpretation tools that allow comparison of bioindicator performance among model scenarios over long (century-scale) time scales. A forest planner can use BAP Toolbox output to design novel management strategies, and also to provide guidance on the implementation of a biodiversity monitoring plan. More information on the BAP Toolbox can be found at http://giant.lakeheadu.ca/carisweb/hsm/bap reports/bap reports main.htm

\section{Concluding Comments}

The models comprising the specific Labrador District 19a toolkit were selected for a variety of reasons, including the relative overlap between model domains and local questions/conditions; the availability, data requirements, and adaptability of existing tools; and the collective experience of the modeling team with those tools. Some of the tools used in the case study may be useful in other applications, but our focus is on a general approach to assembling and building a toolkit that can address specific problems and locations while leveraging research and investment in existing models. The effectiveness of such a toolkit in guiding the SFM planning process is dependent not only on quality tools, but also the degree to which their application and integration promotes information exchange between the key participants in the planning process.

\section{LITERATURE CITED}

Andrewartha, H. G. and L. C. Birch. 1984. The ecological web. More on the distribution and the abundance of animals. University of Chicago Press, Chicago, IL, USA. 
Beaudet, M., C. Messier, and C. D. Canham. 2002. Predictions of understory light conditions in northern hardwood forests following parameterization, sensitivity analysis, and tests of the SORTIE light model. Forest Ecology and Management 165:235-248.

Botkin, D. B., J. F. Janak, and J. R. Wallis. 1972. Some ecological consequences of a computer model of forest growth. Journal of Ecology 60:849-872.

Coates, K. D., C. D. Canham, M. Beaudet, D. L. Sachs, and C. Messier. 2003. Use of a spatiallyexplicit individual-tree model (SORTIE/BC) to explore the implications of patchiness in structurally complex forests. Forest Ecology and Management 186:297-310.

Dixit, A., and R. Pindyck. 1994. Investment under Uncertainty. Princeton University Press, Princeton, New Jersey, USA.

Didion, M., M. J. Fortin, and A. Fall. 2007. Forest age structure as indicator of boreal forest sustainability under alternative management and fire regimes: A landscape level sensitivity analysis. Ecological Modelling 200:45-58.

Doyon, F. and P. N. Duinker. 2003. Assessing forest-management strategies through the lens of biodiversity: A practical case from Central-West Alberta. Pages 207-224 in G. J. Arthaud, and T. M. Barrett, editors. Systems analysis in forest resources. Proceedings of the Eighth Symposium (Snowmass Village, Colorado, U.S.A 2000). Kluwer Academic Publishers, Dordretch. Series: Managing Forest Ecosystems, Volume 7.

Fall, A., D. Daust, and D. G. Morgan. 2001. A framework and software tool to support collaborative landscape analysis: Fitting square pegs into square holes. Transactions in GIS 5:67-86.

Fall, A. and J. Fall. 2001. A domain-specific language for models of landscape dynamics. Ecological Modelling 141:1-18.

Forestry Canada Fire Danger Group. 1992. Development and structure of the Canadian Forest Fire Behavior Prediction System. Forestry Canada, Science and Sustainable Development Directorate, Information Report ST-X-3, Ottawa, Ontario, Canada.

Gustafson, E. J., S. R. Shifley, D. J. Mladenoff, K. K. Nimerfro, and H. S. He. 2000. Spatial Simulation of Forest Succession and Timber Harvesting Using Landis. Canadian Journal of Forest Research 30:32-43.

He, H. S., and D. J. Mladenoff. 1999. Spatially explicit and stochastic simulation of forest-landscape fire disturbance and succession. Ecology 80:81-99.

Hunter, M. L., Jr. 1990. Wildlife, forests and forestry. Principles for managing forests for biodiversity. Prentice Hall, Englewood Cliffs, New Jersey, USA.

Lockwood, C., and Moore, T. 1993. Harvest-scheduling with spatial constraints: a simulated annealing approach. Canadian Journal of Forest Research 23:468-478.

Mladenoff, D. J., G. E. Host, J. Boeder, and T. R. Crow. 1996. LANDIS: a spatial model of forest landscape disturbance succession, and management. pages 175-180 in M. F. Goodchild, L. T. Steyaert and B. O. Parks, editors. GIS and environmental modeling : Progress and research issues. GIS World Books, Fort Collins, Colorado, USA.

Mladenoff, D. J. 2004. LANDIS and forest landscape models. Ecological Modelling 180:7-19.

Pacala, S. W., C. D. Canham, and J. A. Silander, Jr. 1993. Forest models defined by field 
measurements: I. The design of a northeastern forest simulator. Canadian Journal of Forest Research 23:1980-1988.

Pacala, S. W., C. D. Canham, J. Saponara, J. A. Silander, Jr., R. K. Kobe, and E. Ribbens. 1996. Forest models defined by field measurements: Estimation, error analysis and dynamics. Ecological Monographs 66:1-43.

Papaik, M. J., C. D. Canham, E. F. Latty, and K. D. Woods. 2005. Effects of an introduced pathogen on resistance to natural disturbance: Beech bark disease and windthrow. Canadian Journal of Forest Research 35:1832-1843.

Papaik, M. J., and C. D. Canham. 2006. Effects of variation in resistance vs. response to wind disturbance on forest dynamics. Journal of Ecology 94:1011-1026.

Pennanen, J. and T. Kuuluvainen. 2002. A spatial simulation approach to natural forest landscapedynamics in boreal Fennoscandia. Forest Ecology and Management 164:157-175.

Post, W. M. and J. Pastor. 1996. LINKAGES - An individual-based forest ecosystem model. Climatic Change 34:253-261.

Saphores, J.-D. M., and P. Carr. 2000. Real options and the timing of implementation of emission limits under ecological uncertainty. Pages 254-271 in M. J. Brennan and L. Trigeorgis, editors. Project flexibility, agency and competition. Oxford University Press, New York, New York, USA.

Scheller, R. M., and D. J. Mladenoff. 2004. A forest growth and biomass module for a landscape simulation model, Landis: Design, validation, and application. Ecological Modelling 180:211-229.

Scheller, R. M., D. J. Mladenoff, R. C. Thomas, and T. A. Sickley. 2005. Simulating the effects of fire reintroduction versus continued fire absence on forest composition and landscape structure in the Boundary Waters Canoe Area, northern Minnesota, USA. Ecosystems 8:396-411.

Scheller, R. M., J. B. Domingo, B. R. Sturtevant, J. S. Williams, A. Rudy, E. J. Gustafson, and D. J. Mladenoff. 2007. Design, development, and application of LANDIS-II, a spatial landscape simulation model with flexible temporal and spatial resolution. Ecological Modelling 201:409-419

Shugart, H. H., and D. C. West. 1977. Development of an Appalachian deciduous forest succession model and its application to assessment of the impact of the chestnut blight. Journal of Environmental Management 5:161-179.

Simon, N., B. R. Sturtevant, A. Fall, and B. Miranda. 2006. Fire-harvest interactions in central Labrador (Canada): Will harvesting change the fire regime? In Proceedings of the Third International Fire Ecology and Management Congress, November 13-17, 2006; San Diego, CA, USA.

Sturtevant, B. R., E. J. Gustafson, W. Li, and H. S. He. 2004. Modeling biological disturbances in LANDIS: A module description and demonstration using spruce budworm. Ecological Modelling 180: $153-174$.

Uriarte, M. and M. J. Papaik. in press. Hurricane impacts on dynamics, structure, and carbon sequestration potential of forest ecosystems in southern New England. TelusA.

Van Horne, B., and J. A. Wiens. 1991. Forest Bird Habitat Suitability Models and the Development of General Habitat Models. Fish and Wildlife Resource Paper 8. US Department of the Interior, Fish and Wildlife Service, Washington, D.C., USA. 